\title{
S1P-S1PR1 Signaling: the "Sphinx" in Osteoimmunology
}

\author{
Lan Xiao ${ }^{1,2 t}$, Yinghong Zhou ${ }^{1,2,3 \dagger}$, Thor Friis ${ }^{1}$, Kenneth Beagley ${ }^{1,2}$ and Yin Xiao ${ }^{1,2,3 *}$ \\ ${ }^{1}$ Institute of Health and Biomedical Innovation, Queensland University of Technology, Brisbane, QLD, Australia, ${ }^{2}$ The \\ Australia-China Centre for Tissue Engineering and Regenerative Medicine, Queensland University of Technology, Brisbane, \\ QLD, Australia, ${ }^{3}$ Key Laboratory of Oral Medicine, Guangzhou Institute of Oral Disease, Stomatology Hospital of Guangzhou \\ Medical University, Guangzhou, China
}

\section{OPEN ACCESS}

Edited by:

Teun J. De Vries,

VU University

Amsterdam, Netherlands

Reviewed by:

Markus Gräler

Friedrich Schiller University

Jena, Germany

Leyre BM,

UMR5246 Institut de Chimie et

Biochimie Moléculaires et

Supramoléculaires (ICBMS), France

*Correspondence:

Yin Xiao

yin.xiao@qut.edu.au

†These authors have contributed equally to this work

Specialty section

This article was submitted to Inflammation,

a section of the journal

Frontiers in Immunology

Received: 11 February 2019

Accepted: 04 June 2019

Published: 25 June 2019

Citation:

Xiao L, Zhou Y, Friis T, Beagley $K$ and Xiao Y (2019) S1P-S1PR1 Signaling:

the "Sphinx" in Osteoimmunology.

Front. Immunol. 10:1409.

doi: 10.3389/fimmu.2019.01409
The fundamental interaction between the immune and skeletal systems, termed as osteoimmunology, has been demonstrated to play indispensable roles in the maintenance of balance between bone resorption and formation. The pleiotropic sphingolipid metabolite, sphingosine 1-phosphate (S1P), together with its cognate receptor, sphingosine-1-phosphate receptor-1 (S1PR1), are known as key players in osteoimmunology due to the regulation on both immune system and bone remodeling. The role of S1P-S1PR1 signaling in bone remodeling can be directly targeting both osteoclastogenesis and osteogenesis. Meanwhile, inflammatory cell function and polarization in both adaptive immune ( $T$ cell subsets) and innate immune cells (macrophages) are also regulated by this signaling axis, suggesting that S1P-S1PR1 signaling could aslo indirectly regulate bone remodeling via modulating the immune system. Therefore, it could be likely that S1P-S1PR1 signaling might take part in the maintenance of continuous bone turnover under physiological conditions, while lead to the pathogenesis of bone deformities during inflammation. In this review, we summarized the immunological regulation of S1P-S1PR1 signal axis during bone remodeling with an emphasis on how osteo-immune regulators are affected by inflammation, an issue with relevance to chronical bone disorders such as rheumatoid arthritis, spondyloarthritis and periodontitis.

Keywords: osteoimmunology, sphingosine 1-phosphate (S1P), sphingosine 1-phosphate receptor-1 (S1PR1), bone remodeling, immunomodulation

\section{INTRODUCTION}

Skeletal bone undergoes a life-long and continuous renovation termed "bone remodeling," a process that is necessary for bone homeostasis and consists of osteoclasts-driven bone resorption and osteoblasts-driven bone formation (1). Osteoclasts and osteoblasts-derived from immune progenitor cells and mesenchymal stem cells (MSCs), respectively-are linked via immune modulators and are the fundamental cell types of these two interconnected systems. Osteoimmunology, a term first coined at the beginning of this century (2), was identified over forty years ago (3), and describes the interaction between cells from the immune and skeletal systems. The realm of osteoimmunology has revealed a complex system of mutual regulation existing between immune cells and bone cells. This relationship sees the immune response greatly affecting osteoclast-osteoblast coupling, thus mediating the balance between bone resorption and formation, whereas, at another level, cells from the skeletal system have a profound effect on the differentiation and function of immune cells. 
Sphingosine is one of the most important sphingolipid metabolites (4-6). It is named after the Sphinx, a mythical creature of Greek mythology famed for its mysterious features (7). Phosphorylation of sphingosine forms the pleiotropic and bioactive lipid sphingosine-1-phosphate (S1P) (8). S1P is produced by various cell types, which acts not only as an intracellular second messenger, but also an extracellular first messenger in both an autocrine and paracrine manner. It does this by binding with a class of G-protein-coupled receptors, known as sphingosine-1-phosphate receptors (S1PRs), of which there are currently five known subtypes, S1PR1 through to S1PR5 (9). Of these receptors, S1PR1 is expressed in most mammalian cell types and considered to be multifunctional in many biological processes. S1P-S1PR1 signaling has long been addressed as a key regulator of the immune response, due to its involvement in the chemotaxis, activation, differentiation, and function of immune cells (9-13). The elevated concentration of S1P, coupled with an up-regulation of S1PR1 expression locally within inflammatory tissues in many diseases, as well as the therapeutic effects of S1PR1 modulators, is an indication of the important role of S1P-S1PR1 signaling in inflammation $(8,13)$.

S1P-S1PR1 signaling is primarily thought to be a catalyst of inflammation and thereby inducing osteoclastogenesis; however, the fact that this pathway is also active during bone regeneration suggests an enigmatic and rather intriguing role in bone remodeling $(14,15)$. In this review, we will seek to highlight the interactions between the immune and skeletal systems, how these interactions affect bone remodeling, and what is known about the role of S1P-S1PR1 signaling in the emerging field of osteoimmunology.

\section{THE FUNCTION OF S1P AND ITS RECEPTOR S1PR1}

Sphingolipids are a key component of mammalian cell membranes and are metabolized in response to certain stimuli $(4,5)$. Sphingolipids are de novo biosynthesized from serine and palmitate in the endoplasmic reticulum (ER) $(4,5,16,17)$. The condensation of sphingolipids (via the action of serine palmitoyl transferase, SPT) forms 3-keto-dihydrosphingosine $(16,17)$, which is reduced to dihydrosphingosine, then subsequently acylated by (dihydro)-ceramide synthase (also known as Lass or CerS) to form dihydroceramide (18). The desaturation of dihydroceramide forms ceramides (19), the central player in sphingolipid metabolism (20), which could be deacylated by ceramidases (CERase) to produce sphingosines $(21,22)$. Sphingosine could be salvaged through reacylation, a process termed as "salvage pathway" which leading to ceramide regeneration; or it can be phosphorylated to form the multifunctional bioactive lipid S1P, which mediates a number of cellular processes, such as cell proliferation, survival, differentiation, migration, as well as cytokine and chemokine production $(4,5,20,23)$. S1P can be reversibly dephosphorylated to sphingosine by intracellular S1P phosphatases (SPPs) and extracellular lipid phosphate phosphatases, or irreversibly degraded by S1P lyase (SPL) (20, 24-27). In most mammalian cells, S1P levels are held in check by the actions of SPL and SPPs. SPL inhibition via both genetic and pharmacological tools results in tissue S1P accumulation in vivo (28). The exception is platelets, which lack SPL (29), and erythrocytes, which lack both SPL and SPPs (30). This absence explains why, under normal physiological conditions, circulating S1P levels are significantly higher ( $\mu \mathrm{M}$ range) in peripheral blood than in solid tissues. S1P is also maintained at relatively high levels $(>100 \mathrm{nM})$ in the lymphatic circulation, which is mainly due to the presence of lymphatic endothelial cells (31-33). Cells from the macrophagemonocyte lineage are also important producers of S1P (34).

The phosphorylation of sphingosine is performed by sphingosine kinases 1 and 2 (SPHK1 and SPHK2) (35). SPHK1 is mainly present in the cytoplasm which, after being activated by certain stimuli, is translocated to the cell membrane where it catalyzes sphingosine phosphoration (36). On the other hand, SPHK2 distributes not only in cell membrane, but also in organelles such as the ER, mitochondria, as well as in nucleus, which providing S1P for essential cellular processes, such as respiration, histone acetylation, and gene expression (37-39). For example, $\mathrm{S} 1 \mathrm{P}$ is reported to regulate gene expression through modulating HDAC1 and HDAC2 activity $(38,40)$. Intracellular S1P also plays an essential part in tumor-necrosis factor- $\alpha$ (TNF- $\alpha)$ triggered NF- $\kappa \mathrm{B}$ signaling via targeting TNF receptor-associated factor 2 (TRAF2), therefore participating the inflammatory, anti-apoptotic and immune processes (41). Once $\mathrm{S} 1 \mathrm{P}$ is generated, it could be transported to activate its receptors, therefore functioning in a paracrine and/or autocrine manner $(42,43)$. This "inside-out relocation" of S1P is indispensable of special transports, as the polar head group in S1P makes it unable to move through the hydrophobic mammalian cell membranes (44). Transports such as the ATP-binding cassette (ABC) transporters family members have been demonstrated to facilitate S1P transporting in erythrocytes, platelets, and mammalian cells in an ATP-dependent manner (42, 45-49). Another transport, major facilitator superfamily transporter 2b (Mfsd2b) has also been found to play essential roles in exporting S1P in erythrocytes and platelets $(50,51)$. Especially, the transport spinster homolog 2 (SPNS2) is considered as a major regulator in S1P secretion in mammalian cells in a non-ATP dependent manner, which therefore playing essential roles in immune cell development and trafficking, as well as bone homeostasis $(43,52-57)$. Under inflammatory conditions, SPHK1 is abnormally activated to produce high levels of S1P, which is released into the local microenvironment. Inflammatory cytokines such as TNF- $\alpha$, IL- $1 \beta$, and interferon- $\gamma$ (IFN- $\gamma$ ), have been shown to induce SPHK1 in an extracellular signal regulated kinase (ERK) signaling-dependent manner (38, 41, 58-60), and this partially explains the high S1P levels in the inflammatory tissues (61). Furthermore, inflammation is accompanied by vascular leakage, which may allow S1P to permeate from blood to tissues thereby raising the $\mathrm{S} 1 \mathrm{P}$ concentrations within the inflammatory tissues (62).

The secreted S1P regulates pleiotropic biological functions by binding with its receptors (63). Upon activation, the S1P receptors couple with diverse heterotrimeric G-protein subunits

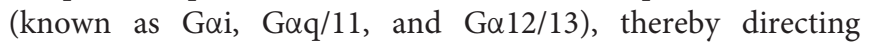


different downstream signaling pathways (64). S1PR1 is the most widely expressed S1P receptor in most tissues, such as the lungs, brain, and especially immune organs (65-67). Following activation by S1P, S1PR1 interacts with G $\alpha$, which then regulates the downstream signaling molecules (Figure 1), such as phospholipase C (PLC), phosphoinositide 3-kinase (PI3K), Ras guanosine triphosphatase (GTPase) and adenylyl cyclase (AC) $(9,68)$. These molecules subsequently activate their downstream signaling pathways (Figure 1), including Rac GTPase, mitogenactivated protein kinase (MAPK), Akt, and mammalian target of rapamycin (mTOR) $(6,9,68,69)$.

S1PR1 has a key role in the development of the vascular system and is highly expressed in differentiating endothelial cells (70). It is required to maintain the integrity of endothelial cell barrier and thus regulates vascular permeability responses, especially under inflammatory conditions (71). When SPHK1 is induced by inflammation, it enhances S1P production in endothelial cells, which then acts in a feed-forward manner to stimulate more S1PR1 expression, counteracting the increased permeability caused by pro-inflammatory mediators e.g., lipopolysaccharides (LPS), thereby preventing otherwise lethal cell-leakage in response to inflammation. The indispensable role of S1PR1 in vascular network stability has been further demonstrated by global S1pr1 gene deletion, which results in defective vascular maturation and then embryonic lethality (70). Specific S1pr1 deletion in endothelial cells results in deformities in the primary vascular plexus (angiogenic hypersprouting), limited blood flow, and vascular leakage (72-75). In epithelial cells, S1PR1 maintains cell barrier integrity and initiates the immune defense against the invading pathogens (76). S1PR1 is expressed in MSCs and regulates cell migration, proliferation, differentiation, and survival (77), whereas in osteoclast- and osteoblast-precursor cells S1PR1 expression is associated with their differentiation (78), further testament to its role in bone remodeling.

\section{THE REGULATORY ROLES OF S1P-S1PR1 SIGNALING IN BONE REMODELING}

\section{Bone Remodeling and Osteoclast-Osteoblast Coupling}

Osteoclasts and osteoblasts are the major players in the bone remodeling process. The hematopoietic stem cells (HSCs)derived osteoclasts are considered as the major type of cells responsible for bone resorption (79). Osteoclastogenesis depends on receptor activator of nuclear factor-kappa B ligand (RANKL), a cytokine in the TNF family (80). RANKL activates its cognate receptor, receptor activator of nuclear factor-kappa $\mathrm{B}$ (RANK), initiating osteoclastogenic signals (Figure S1). The RANKL-RANK axis, together with the downstream NF- $\mathrm{B}$ signaling pathway, is indispensable in osteoclastogenesis (81, 82). Another key factor in osteoclast formation is macrophage colony-stimulating factor (M-CSF), which is critical in regulating survival and proliferation of osteoclast precursors (83).

Osteoblasts are the major producer of RANKL and MCSF (84), indicating that osteoclasts and osteoblasts are related "coupling" cells that link osteoclastogenesis to osteogenesis.
Osteoblasts are derived from MSCs and are the main cell type responsible for bone formation (79). Factors such as alkaline phosphatase (ALP), runt-related transcription factor 2 (RUNX2), osteocalcin $(\mathrm{OCN})$, and the $\mathrm{Wnt} / \beta$-catenin and TGF- $\beta$ signaling pathways, as well as the signal transducer and activator of transcription 3 (STAT3) signaling, are considered to be crucial in osteogenesis (85-89). Besides RANKL and M-CSF, osteoblasts also produce osteoprotegerin (OPG), which, conversely, acts as a decoy receptor of RANKL and thereby impeding osteoclastogenesis (90). Hence, osteoclasts and osteoblasts are interconnected by the RANKL/RANK/OPG axis, with the ratio of RANKL to OPG determining the balance between bone resorption and formation.

Bone remodeling is a strictly regulated process that must maintain bone formation at a rate equal to that of bone resorption (2). Skeletal pathologies arise when this balance is disrupted. The most common one of such disorders is when bone remodeling is skewed toward resorption - that is, when osteoclastogenesis is aberrantly stimulated so the rate of bone resorption exceeds bone formation, resulting in a net bone loss, as seen in inflammatory diseases, such as rheumatoid arthritis (RA) (91), periodontitis (92), and apical periodontitis (93).

\section{The Roles of S1P-S1PR1 in Bone Remodeling}

S1P has been found to induce both osteoclastogenesis and osteogenesis, a dual role that makes S1P-S1PR1 signaling more intriguing.

\section{S1P-S1PR1 Signaling in Osteoclastogenesis}

Together with its ligand S1P, S1PR1 directs chemotactic migration of osteoclast precursors in vitro and in vivo. S1P-S1PR1 signaling is thought to regulate osteoclast precursor trafficking to and from bone surface, where the precursor cells fuse and differentiate into osteoclasts, a process which dynamically regulates bone mineral homeostasis and osteoclastogenesis (78). S1PR1-dependent chemo-attraction is only activated when S1P concentration is comparably low. High concentrations of S1P activates the S1PR2 on the precursor cells and triggers an S1PR2dependent chemo repulsion (94). This mechanism partially explains how these precursor cells are retained in bone marrow, where lower levels of S1P are found than in the peripheral blood. S1PR1 and S1PR2 act in a concerted manner to regulate osteoclast precursors egressing from bone marrow into circulation, depending on the relative concentrations of S1P. It is also found that the active form of vitamin $\mathrm{D}, 1,25-\mathrm{D}$, and its clinically used analog, eldecalcitol (ELD), effectively reduce bone resorption via inhibiting S1PR2 in circulating osteoclast precursors, as S1PR2-blockage directs the migration of osteoclast precursors from bone surface to blood. This study reveals the pharmacologic effect of vitamin D analog in therapy against osteoporosis (95), suggesting that the "S1PR1-S1PR2 concert" should be considered as a therapeutic target for diseases with bone loss. During RANKL-mediated osteoclast differentiation, the activity of SPHK1 is significantly enhanced and increases production of S1P by the precursor cells. Conversely, inhibition of SPHK1 leads to suppression of osteoclastogenesis (34). 


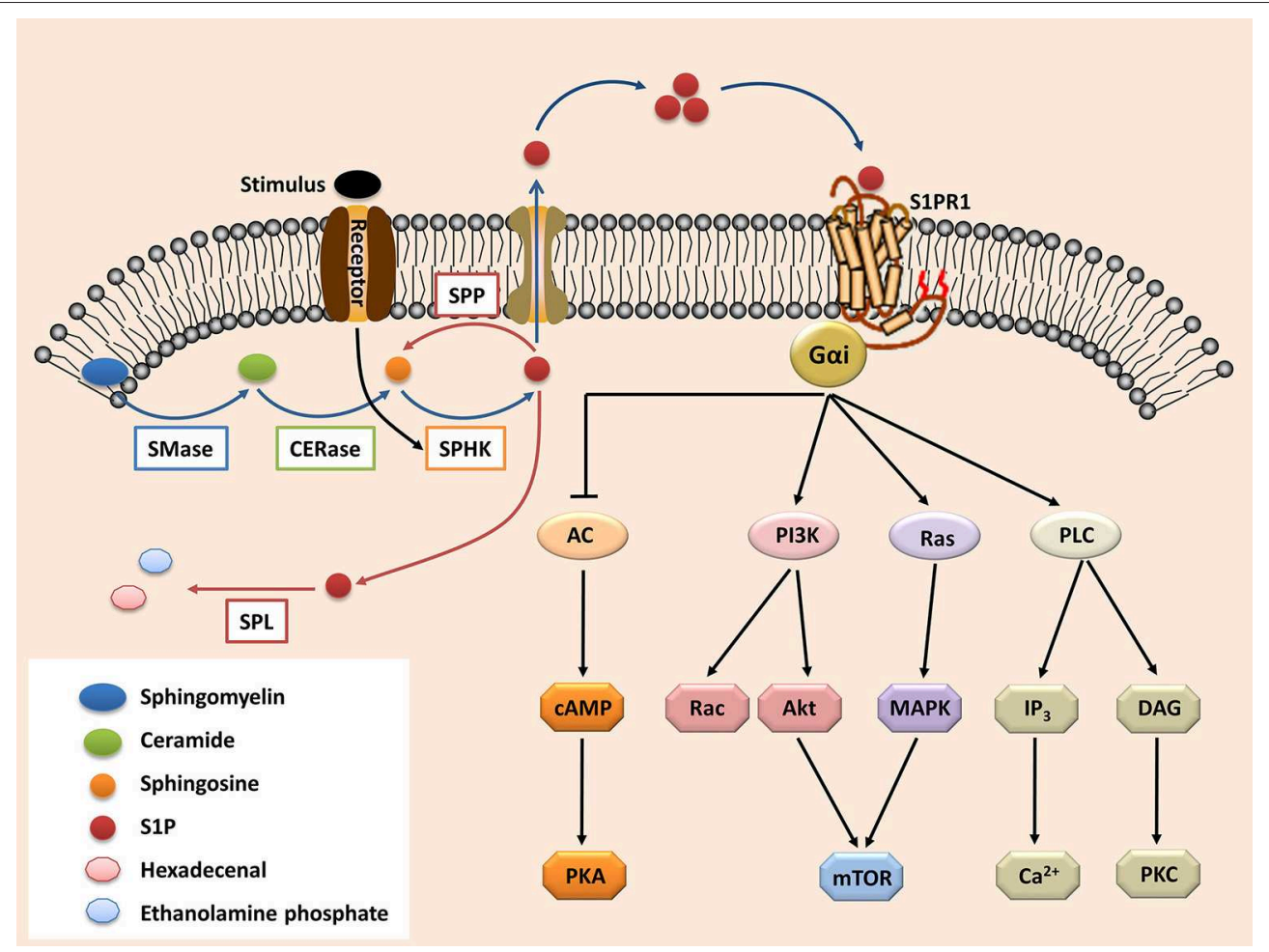

FIGURE 1 | The S1P-S1PR1 signaling. Sphingolipid (derived from cell membrane) is cleaved (by sphingomyelinases, SMase) to ceramide. Ceramide is then deacylated by ceramidases (CERase) to produce sphingosine. S1P is produced by phosphorylation of sphingosine, which is mediated by SPHKs (SPHK1 and SPHK2, which can be activated by certain stimulus). S1P can be reversibly degraded by S1P phosphatases (SPPs), or irreversibly degraded by S1P lyase (SPL). On the other hand, S1P can be transported outside the cells and acts in the autocrine or paracrine manners to activate its receptor S1PR1. The S1PR1 then activates its down-stream signal cascades and therefore regulates diverse cell activities. S1P, sphingosine-1-phosphate; S1PR1, sphingosine-1-phosphate receptor 1; PLC, phospholipase C; PI3K, phosphoinositide 3-kinase; AC, adenylyl cyclase; Ras, Ras GTPase; Rac, Rac GTPase; MAPK, mitogen-activated protein kinase; cAMP, cyclic adenosine monophosphate; mTOR, mammalian target of rapamycin; PKA, protein kinase A; PKC, protein kinase C; DAG, diacylglycerol; IP3, Inositol trisphosphate.

\section{S1P-S1PR1 Signaling in Osteogenesis}

Although S1P is found to induce osteoclastogenesis, it also plays a positive role in osteogenesis. In the process of BMP2-mediated osteoblast differentiation, S1P significantly induces ALP activity and the expressions of key bone formation markers, such as OCN and RUNX2. Enhanced BMP-2/SMAD signaling is the result of MEK (mitogen-activated protein kinase kinase) 1/2-ERK1/2 pathway activation (14). Another study indicates that S1P-S1PR1 signaling activation in osteoblasts mediates the activation of PI3K/Akt signaling and therefore inhibits glycogen

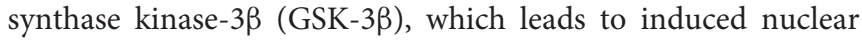
translocation of $\beta$-catenin, a key process in osteogenesis (96). S1P has also been found to induce RUNX2 expression in osteoblasts and thereby improve osteogenesis in vitro and in vivo, which is achieved through S1PR2-dependent activation of Smad1/5/8 signaling (97). Conditioned medium from osteoclasts can induce osteogenesis and is thought to be due to Wnt10b, BMP-6, and $\mathrm{S} 1 \mathrm{P}$ secreted into the medium. And whereas S1P and BMP-6 can trigger the migration of pre-osteoblasts toward bone resorption sites, S1P can also induce osteogenic differentiation of the same cells by activating S1PR1, a finding that becomes apparent when S1PR1 is blocked (15). These properties of S1P-S1PR1 signaling to some degree explain how bone formation is initiated following bone resorption. Accordingly, hormone calcitonin (CT) has been found to block S1P secretion of osteoclast via SPNS2 inhibition, which consequently results in decreased bone formation in vivo in a S1PR3-dependent manner (55). In a more recent study, induced expression and activity of SPHK1 and SPHK2 have been observed during the in vitro osteoblast differentiation, accompanied with enhanced Spns2 gene level, as well as increased S1P secretion. Blockage of SPHK1 or SPHK2 results in retarded osteogenic differentiation and mineralization, suggesting the indispensable role of S1P signaling in osteogenesis (54).

\section{S1P-S1PR1 Signaling in Osteoclast-Osteoblast Coupling}

Interestingly, intracellular S1P, which is produced during osteoclastogenesis, also inhibits this process, by suppressing $\mathrm{p} 38$ MAPK signaling, a key signaling pathway downstream of RANK (Figure S1). This is in contrast with extracellular S1P which has no effect on osteoclast differentiation, suggesting S1P can target cells other than osteoclasts, e.g., the coupling osteoblasts (34). S1P activates p38-MAPK and ERK signaling in osteoblasts, resulting in increased levels of cyclooxygenase-2 (COX2). COX2 induces the expression of prostaglandin E2 (PGE2), which prompts the production of RANKL by osteoblasts. RANKL binds to its receptor RANK on osteoclast precursors which promotes 
osteoclast differentiation and S1P secretion, thereby setting up a feed-forward loop for osteoclastogenesis.

Cathepsin K (CSTK) is an enzyme that is involved in bone degradation which, when specifically deleted in osteoclast lineage by targeted in vivo gene modification, results in a condition characterized by an increased number of osteoblasts and bone formation, as well as an increased number of dysfunctional osteoclasts and impaired bone resorption (98). The in vitro analysis of primary osteoblasts showed enhanced ALP activity and osteogenic potential, as well as increased RANKL/OPG ratio. Osteoclasts from CSTK-knockout mice presented with up-regulated expression of SPHK1 and increased S1P production leading to a higher RANKL/OPG ratio of the primary osteoblasts, which in turn increased the number of osteoclasts. The antagonist of S1PR1 and S1PR3 reduced the osteogenic ability of osteoblasts induced by the conditioned medium of CSTK-deficient osteoclasts, suggesting the enhanced in vivo osteogenesis was due to the activation of S1PR1 and S1PR3 (98).

In a more recent study, S1P degradation was blocked via SPL inhibition (through both genetic and pharmacological means) in vivo, and this resulted in increased bone mass and enhanced bone strength, accompanied with induced OPG expression and reduced osteoclastogenesis in mice (28). Further research revealed the role of S1P-S1PR2 under this phenomenon. In osteoblast, S1P-S1PR2 signaling played a significant role in bone remodeling, which not only promoting the osteogenic differentiation, but also inducing OPG production via $\mathrm{p} 38-\mathrm{GSK} 3 \beta-\beta$-catenin and Wnt5A-LRP5 pathways, suggesting S1P-S1PR2 signaling should improve bone formation while limiting bone resorption. Accordingly, SPL inhibition ameliorated osteoporosis in OPG-deficient mice through inducing the activity and mineralization of osteoblast while reducing osteoclastogenesis. In addition, S1PR2-deficience resulted in osteopenia in mice, accompanied with reduced OPG expression and retarded differentiation of osteoblast (28). These results indicate that similar to S1PR1, S1P-S1PR2 signaling also acts as a coupling factor between osteoclast and osteoblast. However, S1PR2 activation leads to increased OPG production, which possibly neutralizing S1PR1-mediated RANKL expression and hence osteoclastogenesis. It is presumed that S1PR1S1PR2 may act in a balanced way to maintain physiological bone remodeling, while this balance might be destroyed under pathological conditions such as inflammation, which needs further investigation. From these studies, it could be concluded that S1P acts as a coordinator between bone resorption and formation, which, in combination with its positive effects in both osteoclastogenesis and osteogenesis, suggesting a complicated role of this signaling in bone remodeling.

\section{THE IMMUNOMODULATORY ROLE OF S1P-S1PR1 SIGNALING IN OSTEOIMMUNOLOGY}

The balance of bone remodeling is maintained by the immune system, which, therefore, links the skeletal, and immune systems together. As a key regulator of the immune system, the S1PS1PR1 signaling could be postulated to indirectly impact bone remodeling by the immunomodulation, indicating its enigmatic role in osteoimmunology.

\section{Osteoimmunology}

Evidence of the relationship between the immune and skeletal systems became apparent with the finding that IL-1, secreted by antigen-stimulated immune cells, plays a positive role in osteoclastogenesis (99). Since then, many more studies have demonstrated the role of immune system on bone remodeling (Figure 2) (100). Furthermore, cells derived from skeletal system, such as MSCs, are capable of regulating immune responses (101). Such findings gave birth to osteoimmunology, a field that is concerned with interactions between immune and skeletal systems, within which the cells from each system are correlated through a variety of factors and signaling pathways such as S1P-S1PR1.

\section{Regulation of Bone Remodeling by Immune System}

The adaptive immune cells-T-helper cells-play a critical role in bone remodeling by producing RANKL, the key factor in osteoclastogenesis, and also other factors that regulate bone metabolism. Cytokines derived from type 1 helper T (Th1) cells, such as IFN $\gamma$ and granulocyte-macrophage colony-stimulating factor (GM-CSF), suppress osteoclastogenesis by interrupting the RANK signaling (Figure 2) (102-105). However, it is also reported that GM-CSF facilitates the fusion of pre-osteoclasts into multinucleated osteoclasts, suggesting a fundamental role of GM-CSF in the function of osteoclasts $(106,107)$. In addition, GM-CSF derived from breast tumor cells has been found as responsible for osteolytic bone metastasis in vivo (107). Other cytokines derived from type 2 helper $\mathrm{T}$ (Th2) cells, such as interleukin-4 (IL-4) and IL-10, also inhibit RANK signaling and osteoclast differentiation (108-110). IL-6, which is produced by Th2 cells and M1 macrophages, triggers osteoclastogenesis by promoting RANKL production, as well as stimulating IL-1 production, which amplifies the inflammatory response (111113). IL-6 also induces the differentiation of type 17 helper $\mathrm{T}$ (Th17) cells, which secrete the pro-inflammatory cytokine IL-17 $(114,115)$, and in turn promote RANKL secretion and osteoclastogenesis $(116,117)$. The immune-suppressive regulatory $\mathrm{T}$ (Treg) cells (118), inhibit osteoclastogenesis in a direct cell-to-cell contact-dependent manner, by binding of cytotoxic T-lymphocyte-associated protein 4 (CTLA-4) on Treg cells with CD80 and CD86 on osteoclast precursors; Treg cells also reduce osteoclastogenesis by secreting IL-4 and IL-10 (119). Another Treg cell-derived factor, TGF- $\beta$, has pleiotropic effects on osteoclastogenesis. On one hand, TGF$\beta$ can induce osteoclast differentiation by promoting RANK expression and regulate activator protein 1 (AP-1) signaling $(120,121)$, a key downstream effector of RANK (Figure S1). However, in osteoclast-osteoblast co-cultures, TGF- $\beta$ can also suppress RANKL expression in osteoblasts, effectively applying the brakes on osteoclastogenesis (120).

Cells from the innate immune system also contribute to the regulation of osteoclastogenesis. Macrophages, the 


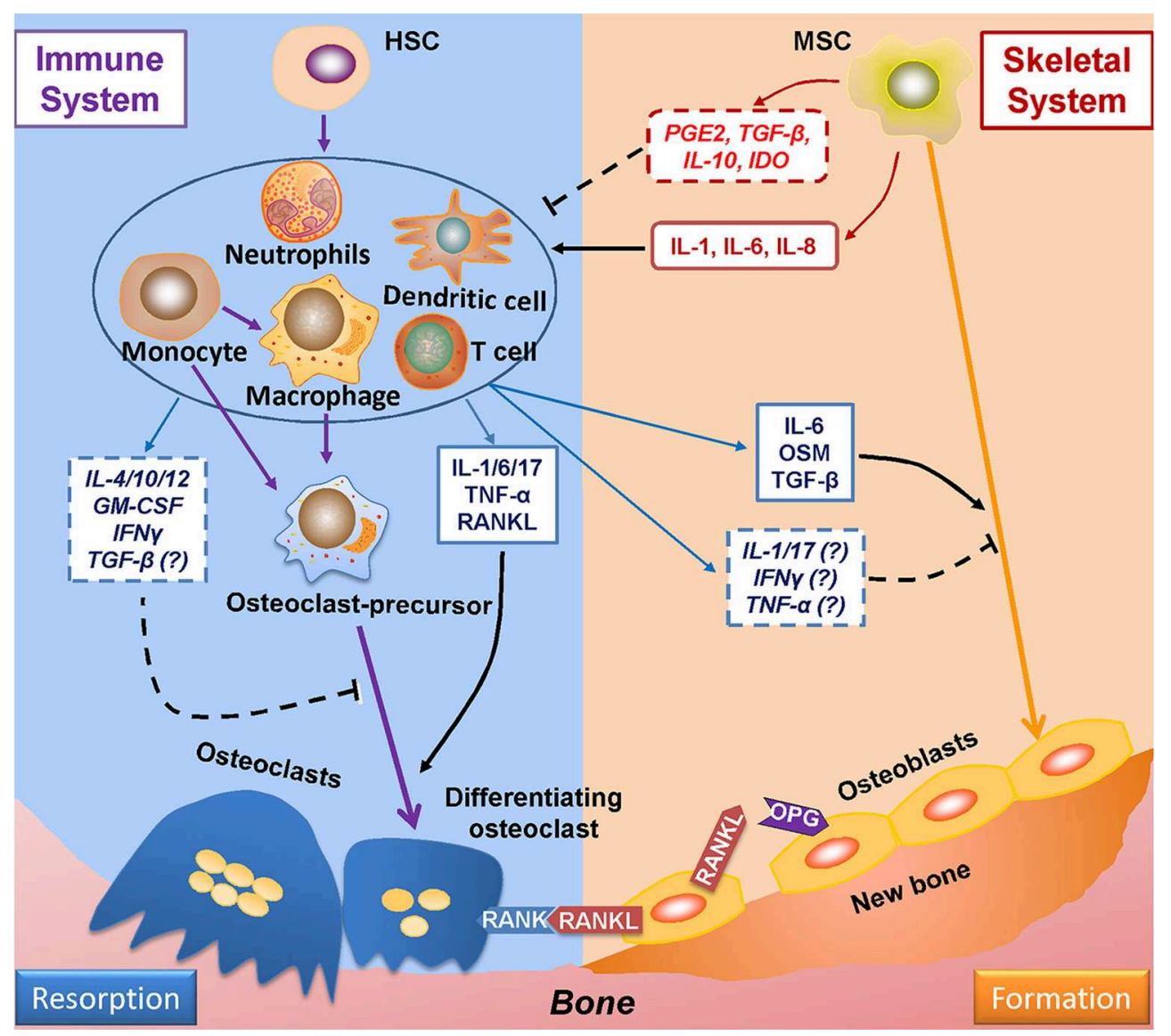

FIGURE 2 | Mutual regulations between the immune and skeletal systems. The two major players in bone remodeling-osteoclasts and osteoblasts are coupled through the RANKL-RANK-OPG axis: osteoblasts-derived RANKL combines with its ligand RANK in osteoclasts and plays an indispensable role in

osteoclastogenesis; OPG (which is also derived from osteoblasts) reduces osteoclastogenesis by impairing the RANKL-RANK signaling. The immune system greatly takes part in osteoclastogenesis by producing RANKL; also, the immune-related factors either affect pre-osteoclasts, or interacts with osteoblasts to induce RANKL production to regulate osteoclastogenesis. The immune-derived regulators also affect the process of osteogenesis. On the other hand, the progenitor cells of the skeleton system-MSCs suppress immune response either by cell to cell intact or by secreting functional regulators; whereas under certain conditions, MSCs upon TLR4 stimulation secret factors which induce immune response. RANKL, receptor activator of nuclear factor factor-kappa B ligand; RANK, receptor activator of nuclear factor-kappa B; OPG, osteoprotegerin.

major components of innate immunity, constitute three subpopulations of cells: (1) non-activated M0 macrophages; (2) proinflammatory M1 macrophages, which are classically activated by LPS or Th1 cell cytokines such as IFN $\gamma$; and (3) M2 macrophages, which is alternatively activated by Th2 cell cytokines, such as IL4 or IL-13, and are classified as anti-inflammatory macrophages (122-125). Macrophages are precursors of osteoclasts (126) and secrete factors that actively affect osteoclastogenesis. M1 macrophages express IL- $1 \alpha$ and IL- $1 \beta$ which activates RANK signaling thereby inducing osteoclastogenesis, under both physiological and pathological conditions (127, 128). M1 macrophages also express TNF- $\alpha$, which stimulates osteoclast differentiation by activating the NF- $\kappa$ B signaling $(129,130)$. Moreover, TNF- $\alpha$ promotes RANKL expression of osteoblasts to induce osteoclastogenesis $(131,132)$. On the contrary, M2 macrophages-derived IL-10 (133) is a negative regulator of osteoclastogenesis (110).
These immune-derived factors also participate in the regulation of osteogenic process. Originated from Treg cells and M2 macrophages, TGF- $\beta$ has been identified as a crucial factor in osteoblast differentiation and mineralization (134). M2 macrophages also recruit MSCs (osteoblast precursors) by producing the transmembrane glycoprotein Osteoactivin (OA)/Glycoprotein non-metastatic melanoma protein B (GPNMB) (135). Interestingly, some pro-inflammatory factors, known as osteoclastogenic promoters, have also been found to induce osteogenesis. For instance, IL-6 can enhance ALP activity in vivo via STAT3 signaling, a further indication of the ability of IL-6 to affect osteogenesis (136-140). Originated from M1 macrophages, oncostatin M (OSM) facilitates osteogenesis by activating RUNX2 via STAT3 signaling pathway. Studies with OSM or OSM receptor (OSMR) deficient mice show reduced bone healing, evidence for its critical role in osteogenesis $(141,142)$. There are studies indicate that IL-1 (143, 144), 
TABLE 1 | Effects of immune cells on bone remodeling.

\begin{tabular}{|c|c|c|c|}
\hline Immune cells & Main functional factors & Effects on osteoclastogenesis & Effects on osteogenesis \\
\hline \multirow[t]{3}{*}{ M1 macrophages } & $\mathrm{IL}-1$ & Activation $(127,128)$ & Activation $(143,144) /$ Inhibition $(148,149)$ \\
\hline & TNF- $\alpha$ & Activation (129-132) & Activation $(147,150) /$ Inhibition $(148,149)$ \\
\hline & OSM & Activation $(151,152)$ & Activation $(141,142)$ \\
\hline \multirow[t]{2}{*}{ M2 macrophages } & $\mathrm{IL}-10$ & Inhibition (110) & Activation (153)/Inhibition $(154,155)$ \\
\hline & TGF- $\beta$ & Dural $(120,121)$ & Activation (134) \\
\hline \multirow[t]{2}{*}{ Th1 cells } & $\mathrm{IFN} \gamma$ & Inhibition (105) & Activation (156, 157)/Inhibition (238) \\
\hline & GM-CSF & Activation(106, 107)/Inhibition (102-104) & Activation (158) \\
\hline \multirow[t]{2}{*}{ Th2 cells } & IL-4 & Inhibition $(108,109)$ & Inhibition (159) \\
\hline & IL-6 & Activation (111-113) & Activation (136-140) \\
\hline Th17 cells & $\mathrm{IL}-17$ & Activation $(114,115)$ & Activation (145, 146)/Inhibition (160) \\
\hline Treg cells & CTLA-4 & Inhibition (119) & - \\
\hline
\end{tabular}

CTLA-4, cytotoxic T-lymphocyte-associated protein 4; GM-CSF, granulocyte-macrophage colony-stimulating factor; IFN $\gamma$, interferon- $\gamma$; IL, interleukin; OSM, oncostatin M; TGF- $\beta$, transforming growth factor- $\beta$; Th, Thelper; TNF- $\alpha$ : tumor necrosis factor $\alpha$; Treg, regulatory $T$.

IL-17 (145, 146), and TNF- $\alpha$ (147) play positive roles in bone formation in vitro and in vivo, however, conflicting results exist (Table 1).

Accumulating evidences indicate that macrophages play an indispensable role in bone formation. The bone residential macrophages are required in osteogenesis and are, more importantly, also needed for the maintenance of boneforming surfaces. Both M1 and M2-derived secreted factors are found to promote osteogenesis, especially M1-derived OSM (142). Interestingly, RANKL is found to induce a M1-like macrophage phenotype; this M1-like macrophage infiltration appears during the early stage of bone repair and is identified to facilitate osteogenesis (167). Furthermore, the conversion of M1 to M2 macrophages significantly improves mineralization of the co-cultured osteoblasts in vitro (168). This is consistent with the in vivo macrophage polarization during bone healing, that the infiltration of M1-like macrophages during the early inflammatory phase is indispensable for bone healing, while the M2-like macrophage infiltration becomes dominant in the later stage of bone repair (167). It can be presumed that the transient activation of M1 macrophages are essential for the early osteoblast activation, while M2 macrophages are indispensable for the later mineralization. Especially, cells from the macrophage-monocyte lineage are considered as important source of S1P (28), a crucial regulator in bone remodeling as discussed above, suggesting that macrophage-derived modulation on bone remodeling might also due to S1P-S1PR1 signaling, which needs further study in the future.

\section{Immune-Regulation Mediated by Cells From Skeletal System}

The skeletal system exerts a regulatory effect on the immune system via the actions of MSCs, which are capable of suppressing the differentiation and function of effector immune cells, such as Th1, Th17, and M1. MSCs can inhibit differentiation of M0 macrophages to dendritic cells (DCs) and suppress their maturation and function. MSCs also induce macrophage polarization to the M2 phenotype and interfere with $\mathrm{T}$ cell proliferation, cytokine production and polarization, in particular the promotion of Treg cell differentiation (101, 169-172). The immune-suppressing functions of MSCs are achieved either through direct cell-cell contact or secretion of soluble immunemodulators, some of which are produced constitutively while others are produced in response to inflammatory factors or activated immune cells (173). Direct cell-cell contact suppression is achieved through the programmed death 1 (PD1) pathway (174), whereas immune suppressive factors include prostaglandin E2 (PGE2), TGF- $\beta$, IL-10, leukemia inhibitory factor (LIF), IL-1 receptor antagonist (IL-1RA) $(173,175)$. Of these factors, PGE2 is considered to be one of the most potent in MSCs' immunosuppressive arsenal, especially in term of macrophage polarization $(101,176)$. MSCs secrete PGE2 in response to pro-inflammatory factors, such as IFN $\gamma$ or LPS $(171,177)$ and convert M1 macrophages to M2 phenotype (178). This process, which depends on PGE2, induces the production of immune suppressive cytokines (such as IL-10), while impeding the secretion of pro-inflammatory cytokines (such as TNF- $\alpha$ and IL-6), resulting in a microenvironment more suitable for tissue regeneration $(171,179)$. These effects of PGE2 directly affect the immune response and acts as a coupling factor between macrophages and MSCs/pre-osteoblasts in a way that facilitates osteogenesis (180).

However, when toll-like receptors (TLRs) are activated by LPS, IFN- $\alpha / \gamma$, or TNF- $\alpha$, MSCs can respond by producing pro-inflammatory cytokines (173) such as IL-1 $\beta$ and IL6 and the chemokine IL-8, which attract the migration of neutrophils and augment the inflammatory response (181). It has emerged that similar to macrophages, human MSCs also polarizes into two distinct phenotypes: pro-inflammatory MSC1 and immunosuppressive MSC2 (182). TLR signaling plays an active role in this polarization, in which acute and low-level activation of TLR4 directs MSCs toward the MSC1 phenotype, whereas the TLR3 activation induces an MSC2 phenotype. The MSC1 phenotype can also be induced by IFNs or direct contact with certain pro-inflammatory cells. Polarized MSCs 
TABLE 2 | Possible effects of S1P-derived immune-regulation on bone remodeling.

\begin{tabular}{|c|c|c|c|}
\hline \multirow[t]{2}{*}{ Cell type } & \multirow{2}{*}{$\begin{array}{l}\text { Immune- } \\
\text { regulation of } \\
\text { S1P }\end{array}$} & \multicolumn{2}{|c|}{$\begin{array}{l}\text { Possible effects on bone } \\
\text { remodeling }\end{array}$} \\
\hline & & Osteoclasto-genesis & Osteogenesis \\
\hline M1 macrophages & $\begin{array}{l}\text { Differentiation } \downarrow \\
\text { (161) }\end{array}$ & $\downarrow$ & $\uparrow$ \\
\hline M2 macrophages & $\begin{array}{l}\text { Differentiation } \uparrow \\
\text { (161) }\end{array}$ & $\downarrow$ & $\uparrow$ \\
\hline Th1 cells & $\begin{array}{l}\text { Response } \downarrow \\
(162)\end{array}$ & $\downarrow$ & $\uparrow$ \\
\hline Th2 cells & $\begin{array}{l}\text { Response } \uparrow \\
\text { (163) }\end{array}$ & $\downarrow$ & $\uparrow$ \\
\hline Th17 cells & $\begin{array}{l}\text { Differentiation } \uparrow \\
(164,165) \\
\text { Response } \uparrow \\
(164,165)\end{array}$ & $\uparrow$ & $\uparrow(?)$ \\
\hline Treg cells & $\begin{array}{l}\text { Differentiation } \downarrow \\
(165,166)\end{array}$ & $\uparrow$ & - \\
\hline
\end{tabular}

Th, Thelper; Treg, regulatory $T$.

are thought to play roles similar to that of M1 and M2 macrophages in tissue repair (183), with MSC1s contributing to early stage inflammation and MSC2s contributing to late tissue regeneration. Of note, a recent study has found that macrophage-derived inflammatory factors could induce the RANKL production of bone marrow stromal cells through the SPHK1-S1PR1 axis (184), suggesting that S1P-S1PR1 signaling might participate in MSC polarization and therefore in turn regulate immune response.

\section{Roles of S1P-S1PR1 in Osteoimmunology}

When S1P binds with S1PR1, it forms a complex that governs a diverse range of immune cell activities, such as cell migration, proliferation, and differentiation (185). This immunomodulatory effect is thought to be pivotal for bone remodeling (Figure 3).

S1P-S1PR1 signaling plays a decisive role in regulating the traffic and egression of immune cells, such as HSCs, DCs, macrophages (monocytes), neutrophils, mast cells, T and B lymphocytes, natural killer T (NKT) cells (78, 186-193). Under both homeostatic and pathological conditions, S1PS1PR1 signaling is required for mature thymocytes to egress from the thymus, as are T/B cells from secondary lymphoid tissues into blood or lymph (188, 194-196). S1PR1 deficiency results in blocked lymphocyte egression, a condition known as lymphopenia (196), suggesting a vital role for S1PR1 in the timely and appropriate distribution of immune cells, a process that aids homeostasis of the immune system. During inflammation, there is a spike of the local concentration of S1P, results in activated S1PR1 and the recruitment of immune cells-such as effector $\mathrm{T}$ cells - to the inflamed tissues and their in situ retention (61), which therefore promotes the inflammatory response-a process that induces bone resorption (100).

S1P-S1PR1 signaling is also an essential modulator of immune cell differentiation and function. S1P is required for the maturation and function of DCs, which further affects the activation and polarization of $\mathrm{CD}^{+} \mathrm{T}$ cells $(197,198)$.
S1P regulates the function and especially the polarization of $\mathrm{CD}^{+}{ }^{+} \mathrm{T}$ cell subsets. S1PR1 activation in $\mathrm{CD} 4^{+} \mathrm{T}$ cells impairs the production of IFN $\gamma$ by Th1 cells, while enhance the production of Th2 cells-derived effector cytokine IL-4, thereby downregulating the Th1 cell response while upregulating that of Th2 cells $(162,163,199,200)$. On the other hand, S1P can induce the differentiation and activation of Th17 cells, as well as the production of IL-17 in vitro (Table 2)-both of which promote osteoclastogenesis (201). This is accompanied by reduced production of Th1 and Th2 cell-derived cytokines, a process that is considered to be S1PR1-dependent (164, 165). Furthermore, signaling through S1PR1 impedes the differentiation and function of Treg cells, the vital suppressor in immune response and osteoclast differentiation (118), by activating the downstream Akt-mTOR signaling pathway (166, 202), thereby exacerbating bone resorption (Table 2). More importantly, by enhancing RANKL production in $\mathrm{CD}^{+} \mathrm{T}$ cells S1P contributes to osteoclastogenesis (203).

However, in macrophage polarization, S1P-S1PR1 signaling tends to favor differentiation to an anti-inflammatory phenotype, inducing a conversion of the M1 to M2 subset (161). The S1P-derived induction of Th2 response and IL-4 secretion may indirectly affect this process. The shift from M1 toward the M2 subset (161) could be considered as reducing osteoclastogenesis, since the M1 macrophage-derived cytokines are recognized as inducers for osteoclast differentiation (Table 1). A similar shift may also take place in osteogenesis in which M1 macrophages, indispensable during the early stages of bone repair, shift toward the M2 phenotype that is required in the later stages of bone formation $(142,168)$. Therefore, in contrast to its immune-inductive role in $\mathrm{CD}^{+} \mathrm{T}$ cell polarization, S1PS1PR1 signaling has an immune-suppressive role in determining macrophage polarization, which complicates its role in bone remodeling (Table 2 ).

From these studies, a picture emerges of how S1P modulate osteoimmunology (Figure 4). Under physiological conditions, $\mathrm{S} 1 \mathrm{P}$ secreted from osteoclasts during normal bone resorption may initiate bone formation. S1P prompts the migration and subsequent differentiation of MSCs to the resorption pits and also promotes the secretion of PGE2. The combined effect of S1P and PGE2 determines macrophage phenotype and creates a microenvironment suitable for bone regeneration. On the other hand, S1P and PGE2 induce the RANKL expression of osteoblasts. Osteoclast-precursors, which are also recruited by $\mathrm{S} 1 \mathrm{P}$, migrate to the resorption site where they are exposed to osteoblast-derived RANKL, which promotes their differentiation into mature osteoclasts, thus underpinning the continuous process of bone remodeling. Under pathological conditions, such as inflammation, the effects of S1P and PGE2 on macrophages are counteracted by inflammatory cytokines, which interfere with the conversion of M1 to M2 macrophages, resulting in a microenvironment that is unfavorable to osteogenesis. This is further exacerbated once the MSCs stop being immunosuppressive and exhibit a proinflammatory phenotype. T cells are also activated by S1P, which infiltrate in the site of resorption and secrete more RANKL into the local microenvironment. The high concentration of RANKL and inflammatory cytokines leads to a catabolic 


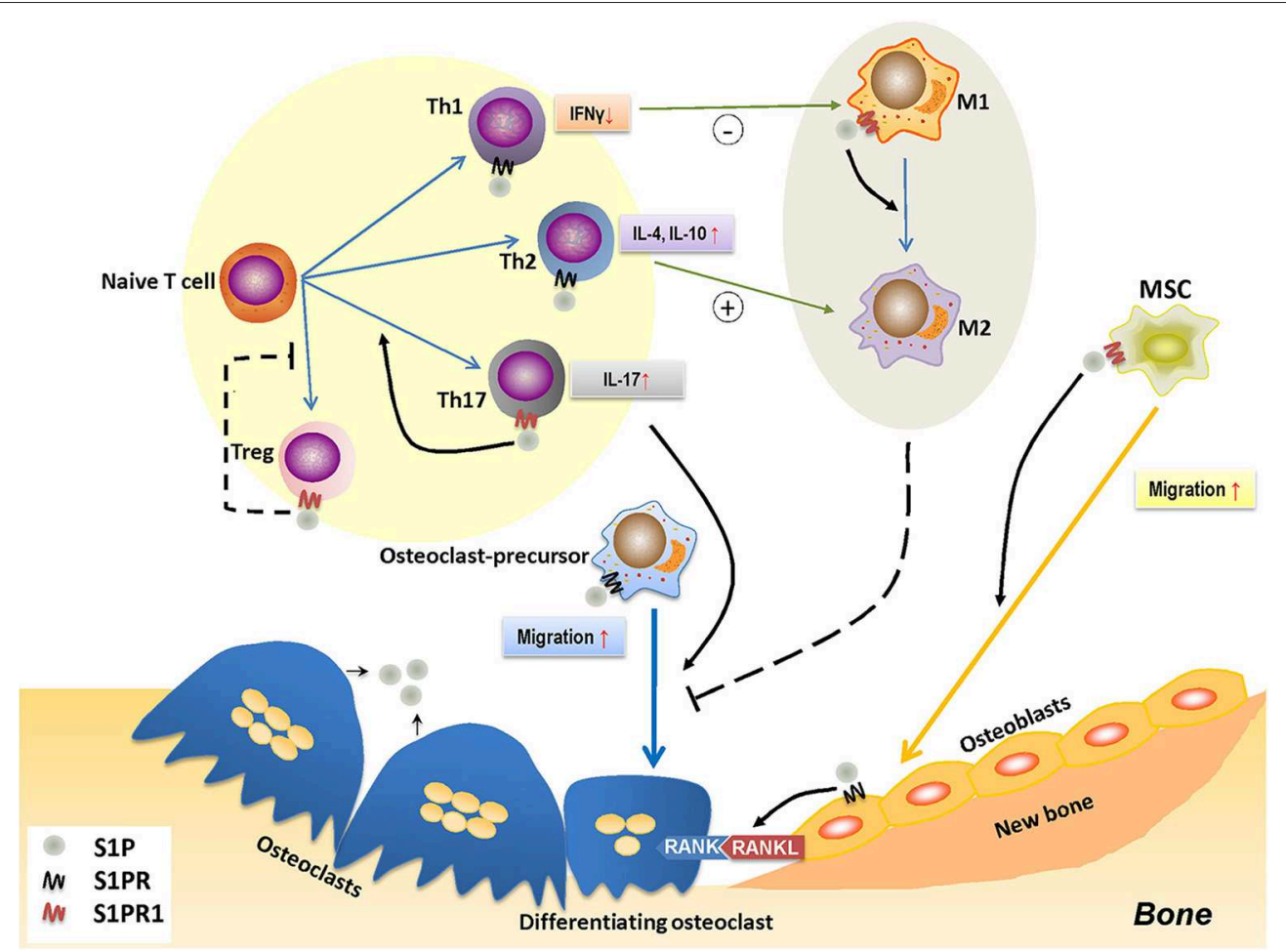

FIGURE 3 | The role of S1P-S1PR1 signaling in osteoimmunology. S1P-S1PR1 signaling is greatly involved in the interaction between immune system and bone remodeling. On one hand, S1PR1 directly affects osteoclastogenesis by inducing the migration of osteoclast-precursors. The direct effect of S1P on osteoclast-precursors results in reduced osteoclastogenesis; however, it induces RANKL production of osteoblasts and facilitating the RANKL-RANK mediated osteoclastogenesis. S1P also induces the migration of MSCs and osteogenesis by activating S1PR1. On the other hand, S1P-S1PR1 signaling participates in immune regulation, which affects the polarization and function of T-helper cells. S1P-S1PR1 signaling induces the differentiation and function of Th17 cells (known as inducing osteoclastogenesis) while impedes that of Treg cells (known as reducing osteoclastogenesis); therefore facilitating osteoclastogenesis. S1P also induces the function of Th2 cells while reduces that of Th1 cells, which affects the macrophage phenotype; also, S1P directly induces the transition of M1 to M2 phenotype by activating S1PR1. This conversion of pro-inflammatory M1 macrophages to tissue-engineering M2 macrophages therefore impedes osteoclastogenesis, which might also affect osteogenesis. S1P, sphingosine-1-phosphate; S1PR, sphingosine-1-phosphate receptor(s); S1PR1, sphingosine-1-phosphate receptor 1; MSC, mesenchymal stem cell; Th1/2/17, type 1/2/17 helper T cell; M1/M2, M1/M2 macrophage; Treg, regulatory T cell; IFN $\gamma$, interferon- $\gamma$; IL-4/10/17, interleukin-4/10/17.

imbalance that favors bone resorption. Of note, it is still unclear whether S1P signaling leads to "normal" or "abnormal" bone formation, as elevated S1P has also been found in diseases with unwanted excessive bone formation such as spondyloarthritis $(54,204)$.

Taken together, the weight of evidence all points to S1PS1PR1 signaling having a pivotal role in osteoimmunology. At one level there is a direct link between S1P-S1PR1 and osteoclast-osteoblast coupling; however, there is also an indirect link that affects bone remodeling via S1P-S1PR1 regulation of immune response. Under certain pathological conditions, this finely tuned system is thrown into disequilibrium resulting in an overactive immune environment where bone resorption outstrips formation.

\section{S1P-S1PR1 SIGNALING IN BONE DISEASES}

Abnormally activated S1P-S1PR1 signaling has been observed in many diseases, such as RA, multiple sclerosis and cancer
(205-207). The importance of S1P-S1PR1 signaling in osteoimmunology highlights the need to assess its roles in the pathogenesis of bone diseases. In addition, S1P regulation via SPL inhibition has been demonstrated to enhance bone mass and strength in a S1PR2-dependant manner in vivo, which also effectively ameliorating osteoporosis in S1PR2-deficient mice, suggesting S1P is a potential therapeutic target for bone diseases (28).

$\mathrm{RA}$ is an autoimmune disorder of the joints characterized by excessive osteoclastogenesis-the result of inflammatory immune response (206). Activated S1P-S1PR1 signaling is found in the synovial tissues of RA joints (206), which is considered to promote RANKL production of $\mathrm{CD} 4^{+} \mathrm{T}$ cells and synoviocytes in a COX-2-dependant manner (203). The joint and bone destruction is significantly alleviated in Sphk1deficient mice: the reduced circulating S1P leads to limited COX-2 expression and Th17 differentiation, with a resulting inhibition of osteoclastogenesis in inflammatory joints (208). Fingolimod, also known as FTY720, is a sphingosine analog that acts as a modulator of S1P-S1PR1 signaling, which has been clinically used in treatment against multiple sclerosis 


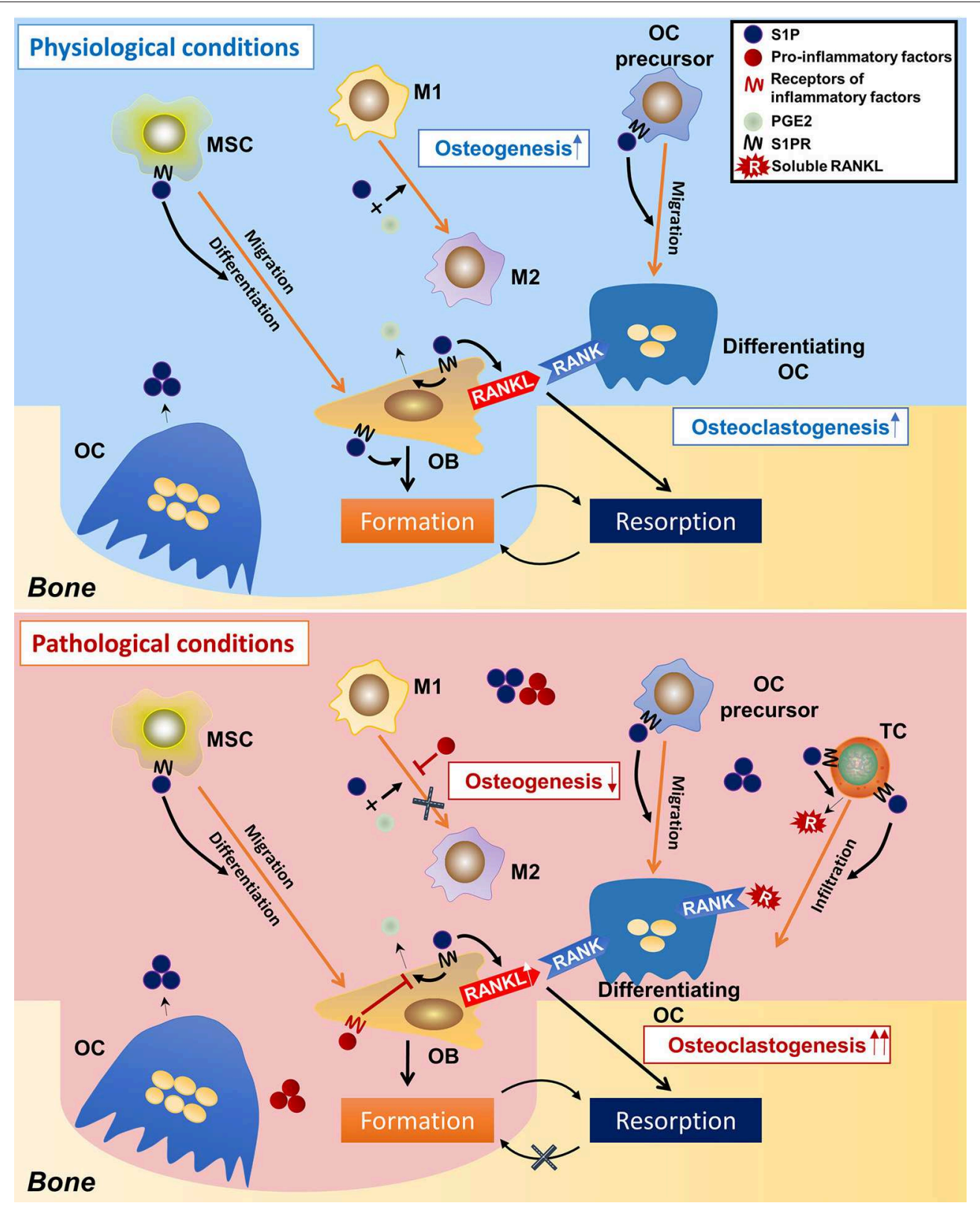

FIGURE 4 | Speculations on the regulatory roles of S1P on osteoimmunology under physiological and pathological conditions. In the physiological condition, osteoclast-derived S1P initiates bone formation by triggering MSCs migration to the resorption cite and by inducing osteoblasts differentiation. During the osteogenic process, S1P also induces the production of PGE2, which, together with S1P, leads the polarization of macrophages toward the M2 phenotype, thereby facilitating bone formation. S1P also induces RANKL production of osteoblasts, as well as the migration of osteoclast-precursors, initiating a new round of osteoclastogenesis. This makes the constant remodeling and bone metastasis. However, in the pathological condition (inflammation), the over-accumulated S1P results in infiltration of inflammatory cells (i.e., T-helper cells), which not only secret large amounts of pro-inflammatory cytokines, but also produce a lot of RANKL (in stimulation of S1P), which greatly induces osteoclastogenesis. On the other hand, the pro-inflammatory factors neutralize the immune-suppressive function of S1P and PGE2 on macrophages, result in failed conversion from M1 to M2 phenotype-an unsuitable circumstance for osteogenesis. This eventually makes to the imbalance between bone resorption and formation and thereby bone loss. S1P, sphingosine-1-phosphate; S1PR, sphingosine-1-phosphate receptor(s); MSC, mesenchymal stem cell; M1/M2, M1/M2 macrophage; OC, osteoclast; OB, osteoblast; TC, T cell; PGE2, prostaglandin E2.

(209). FTY720 is phosphorylated by SPHK2 (FTY720-P) in vivo to gain high affinity to S1PR1 $(210,211)$. Although both S1P and FTY720-P induce S1PR1 internalization $(212,213)$, the endocytosed S1PR1 following S1P binding is eventually recycled back to cell surface (212); while the endocytosed S1PR1 induced by FTY720-P is then irreversibly degraded (184, 213-217), resulting a pharmacologic deletion of S1PR1 from cell surface (218). FTY720 has been demonstrated 
to be effective in a mouse RA model, which inhibited the infiltration of effector $\mathrm{CD}^{+} \mathrm{T}$ cells and reduced IL- 6 and TNF- $\alpha$ expression in synovial fibroblast cells (219). Similar results have been found in adjuvant-induced arthritis (AA) and collagen-induced arthritis (CIA) rodent models, which were achieved via modulating the migration of T cells and DCs, as well as regulating $\mathrm{T}$ cell polarization (220-222), suggesting that S1PR1-deletion could be a pharmacological strategy for RA. Interestingly, strategies to increase S1P also showed therapeutic effects in RA animal models. SPL inhibitors, (E)-1-(4-((1R, 2S,3R)-1,2,3,4-Tetrahydroxybutyl)-1H-imidazol-2-yl)ethanone Oxime (LX2931) and (1R,2S,3R)-1-(2-(Isoxazol-3-yl)-1Himidazol-4-yl)butane-1,2,3,4-tetraol (LX2932) have been found to reduce symptoms and pathological changes in the RA mice model, which could dose-dependently decrease the numbers of circulating lymphocytes by sequestrating them in the thymus (223). In phase I clinical trial, LX2931 administration effectively decreased peripheral lymphocyte counts, suggesting it could potentially reduce local inflammation in RA patient (223). The similar effects between S1P induction and S1PR1 reduction indicate that other S1PRs such as S1PR2, which has demonstrated effects against S1PR1 $(28,94)$, should also be considered as therapeutic target for RA in the future.

Besides RA, S1P signaling might also participate in the pathogenesis of other arthritis such as spondyloarthritis. Spondyloarthritis (SpA) is a group of several inner-related disorders: psoriatic arthritis, arthritis related to inflammatory bowel disease, reactive arthritis, a subgroup of juvenile idiopathic arthritis, as well as ankylosing spondylitis (the prototypic subtype) (224). Spondyloarthritis is characterized by enthesopathy-inflammation at the cites (named as enthesis) where ligaments and tendons attach to the bone through fibrocartilage connections $(54,224)$. SpA at later stage usually results in abnormities at enthesis such as excessive bone formation, increased mineralization and fusion of bone, as well as ankyloses (54). A recent study has found that the S1P levels in serum from SpA patients are significantly induced, as compared with those from healthy donors (54, 204). S1P has also been found to induce the mineralization of primary chondrocytes and osteoblasts originated from enthesis (54). This suggests the accumulation of S1P may result in the excessive ossification in $\mathrm{SpA}$, which still needs further verification (54).

S1P is also strongly associated with the pathogenesis of infection-related inflammatory bone loss, as seen in periodontitis and periapical lesions: an inflammatory condition caused by teeth-related bacterial infections that erodes alveolar bone. In a mouse periodontitis model, the ablation of SPHK1 can significantly attenuate alveolar bone loss and is accompanied by a reduction in the numbers of leukocytes and osteoclasts in the periodontal tissues (225). S1P-S1PR1 signaling is also linked to periapical lesions: an upregulation of S1PR1 positively correlates with RANKL and osteoclast expression and negatively with the number of Treg cells during the pathogenesis of periapical bone destruction (226). Further research into this phenomenon indicates that infection-induced M1 macrophages interact with osteoblast-precursors to enhance the production of S1P, which acts in an autocrine manner to activate S1PR1 on osteoblast-precursors. The activation of S1P-S1PR1 signaling results in induced RANKL production, which is partially achieved through the mTOR signaling-dependent inhibition of autophagy in osteoblast-precursors (184). These studies suggest modulation of S1P-S1PR1 signaling could be a novel therapeutic strategy for infection-induced inflammatory bone diseases.

\section{FUTURE DIRECTIONS AND CONCLUSION}

Although S1P has been studied for years, many questions still remain un-resolved regarding its role in bone remodeling. For instance, the actual outcome of S1P-S1PR1 signaling-derived modulation on bone remodeling is unknown, since it is found to induce both osteoclastogenesis and osteogenesis. The role of S1P-S1PR1 signaling in osteoimmunology is even more complicated, as its downstream signaling pathway, mTOR, has a dual role in immune system, that in Th cells it directs the polarization toward inflammatory phenotype, while in macrophages it directs the anti-inflammatory M2 polarization (125, 227-229). Until now the detailed cross-talk between immune and skeletal systems over bone regeneration remains unclear, further investigation on different types of infiltrating immune cells, as well as their mutual-regulations during bone regeneration, would help to understand the ultimate role of S1P-S1PR1 signaling in osteoimmunology. It could be presumed that this signaling takes part in the maintenance of the balance between bone resorption and formation under physiological conditions. Especially under inflammatory conditions, a question arises about whether the activated S1P-S1PR1 signaling would trigger osteogenesis in osteoblast-precursors, and it could be proposed that this signaling plays a role in the pathogenesis of inflammation-related bone sclerosis lesions, such as bone spurs in arthritis or sequestrum in osteomyelitis. Another question lies in the mechanism and outcome of S1P-S1PR1 mediated osteogenesis: it has been proved that S1P-S1PR1 leads to induced Wnt- $\beta$-catenin signaling pathway to improve osteoblast differentiation (96); however, if $\beta$-catenin induction continues, it would result in interrupted Notch signaling and therefore should interfere the terminal differentiation toward osteocytes, as it has been identified that Wnt and Notch pathways are mutually exclusive during osteogenesis; and the up-regulated Notch signaling plays indispensable roles in osteocyte differentiation, while Wnt signaling is more dominant during osteoblast differentiation (230). Also, S1PS1PR1 activation will leads to the activation of mTOR signaling $(166,202)$. Although mTOR has been found to play decisive roles in the transition from pre-osteoblasts to osteoblasts (231233), however, it acts as an inhibitor in the autophagyan indispensable process in extracellular calcium deposition during mineralization (234-239). It could be presumed that S1P-S1PR1-Akt-mTOR signaling pathway should play positive roles during early stage osteoblast differentiation, however, the later stage osteocyte differentiation as well as mineralization 
might be affected; also, the quality of such mineralization might be abnormal or even pathological, as compared with the physiological ones.

In summary, S1P, a key coupling factor for osteoclasts and osteoblasts, plays a complex role in bone remodeling by targeting both osteoclastogenesis and osteogenesis. The immunomodulatory feature of S1P-S1PR1 signaling further indicates that favors the inflammatory cell phenotypes in the adaptive immune system ( $\mathrm{T}$ cell subsets), while induces macrophage polarization toward the antiinflammatory phenotype. This dual role in immune system indicates that S1P-S1PR1 signaling might take part in the maintenance of continuous bone turnover under physiological conditions, while lead to the pathogenesis of bone deformities during inflammation. Further investigation of the S1P-S1PR1 signaling pathway should help to get a better understanding about osteoimmunology and therefore benefit the clinical approach for inflammatory bone disorders.

\section{AUTHOR CONTRIBUTIONS}

All authors listed have made a substantial, direct and intellectual contribution to the work, and approved it for publication. LX involved in the concept and design of the article, wrote the manuscript. YZ involved in the conception and design of the article, reviewed the manuscript. TF assisted with manuscript preparation. $\mathrm{KB}$ reviewed the manuscript. YX involved in the conception and design of the article, and reviewed the manuscript.

\section{REFERENCES}

1. Raggatt LJ, Partridge NC. Cellular and molecular mechanisms of bone remodeling. J Biol Chem. (2010) 285:25103-8. doi: 10.1074/jbc.R109. 041087

2. Arron JR, Choi Y. Osteoimmunology: bone versus immune system. Nature. (2000) 408:535-6. doi: 10.1038/35046196

3. Horton JE, Raisz LG, Simmons HA, Oppenheim JJ, Mergenhagen SE. Bone resorbing activity in supernatant fluid from cultured human peripheral blood leukocytes. Science. (1972) 177:793-5. doi: 10.1126/science.177.4051.793

4. Gault CR, Obeid LM, Hannun YA. An overview of sphingolipid metabolism: from synthesis to breakdown. Sphingolipids Signal Regulat Molecules. (2010) 688:1-23. doi: 10.1007/978-1-4419-6741-1_1

5. Hannun YA, Obeid LM. Sphingolipids and their metabolism in physiology and disease. Nat Rev Molecul Cell Biol. (2018) 19:175-91. doi: 10.1038/nrm.2017.107

6. Takabe K, Paugh SW, Milstien S, Spiegel S. "Inside-out" signaling of sphingosine-1-phosphate: therapeutic targets. Pharmacol Rev. (2008) 60:181-95. doi: 10.1124/pr.107.07113

7. Thudichum JLW. A Treatise on the Chemical Constitution of the Brain. London: Archon Books (1962).

8. Maceyka M, Harikumar KB, Milstien S, Spiegel S. Sphingosine-1-phosphate signaling and its role in disease. Trends Cell Biol. (2012) 22:5060. doi: 10.1016/j.tcb.2011.09.003

9. Kihara Y, Maceyka M, Spiegel S, Chun J. Lysophospholipid receptor nomenclature review: IUPHAR Review 8. Br J Pharmacol. (2014) 171:357594. doi: 10.1111/bph.12678

\section{FUNDING}

This study was provided by the National Natural Science Foundation of China (NSFC, Grant No. 31771025), the National Natural Science Foundation of China (NSFC) Young Scientists Fund (Grant No. 81700969), the National Health and Medical Research Council (NHMRC) Early Career Fellowship (Grant No. 1105035).

\section{ACKNOWLEDGMENTS}

This study includes content from LX's thesis Dissecting the role of sphingosine 1-phosphate sphingosine 1-phosphate receptor 1 in inflammatory bone remodeling (240). This study has only appeared in this thesis, and the inclusion is in line with the policy of Queensland University of Technology.

\section{SUPPLEMENTARY MATERIAL}

The Supplementary Material for this article can be found online at: https://www.frontiersin.org/articles/10.3389/fimmu. 2019.01409/full\#supplementary-material

Figure S1 | The RANKL-RANK axis mediated osteoclastogenic signals. RANK is activated when combining with its ligand RANKL. Activated RANK then triggers the down-stream osteoclastogenic signaling cascades. Activated TRAF6 induces the MAPK, IKK, and NF-кB signaling, which eventually result in activation of NFATc1 and osteoclastogenesis. RANKL: receptor activator of nuclear factor factor-kappa B ligand. RANK, receptor activator of nuclear factor-kappa B; TRAF6, tumor-necrosis factor (TNF) receptor-associated factor 6; IKK, inhibitor of nuclear factor kappa-B kinase; MAPK, mitogen-activated protein kinase; NF-кB, nuclear factor kappa B; AP-1, activator protein1; ERK, extracellular signal regulated kinase; JNK, c-Jun N-terminal kinase; NFATc1, nuclear factor of activated T-cells, cytoplasmic 1.
10. Yanagida K, Hla T. Vascular and immunobiology of the circulatory sphingosine 1-phosphate gradient. Annu Rev Physiol. (2017) 79:6791. doi: 10.1146/annurev-physiol-021014-071635

11. Obinata H, Hla T. Sphingosine 1-phosphate and inflammation. Int Immunol. (2019) 2019:dxz037. doi: 10.1093/intimm/dxz037

12. Mendoza A, Fang V, Chen C, Serasinghe M, Verma A, Muller J, et al. Lymphatic endothelial S1P promotes mitochondrial function and survival in naive T cells. Nature. (2017) 546:158. doi: 10.1038/nature22352

13. Aoki M, Aoki H, Ramanathan R, Hait NC, Takabe K. Sphingosine1-phosphate signaling in immune cells and inflammation: roles and therapeutic potential. Mediat Inflamm. (2016) 2016:8606878. doi: 10.1155/2016/8606878

14. Sato C, Iwasaki T, Kitano S, Tsunemi S, Sano H. Sphingosine 1-phosphate receptor activation enhances BMP-2-induced osteoblast differentiation. Biochem Biophys Res Commun. (2012) 423:200-5. doi: 10.1016/j.bbrc.2012.05.130

15. Pederson L, Ruan M, Westendorf JJ, Khosla S, Oursler MJ. Regulation of bone formation by osteoclasts involves Wnt/BMP signaling and the chemokine sphingosine-1-phosphate. Proc Natl Acad Sci USA. (2008) 105:20764-9. doi: 10.1073/pnas.0805133106

16. Hannun YA, Obeid LM. The ceramide-centric universe of lipid-mediated cell regulation: stress encounters of the lipid kind. J Biol Chem. (2002) 277:25847-50. doi: 10.1074/jbc.R200008200

17. Linn S, Kim H, Keane E, Andras L, Wang E, Merrill A. Regulation of de novo sphingolipid biosynthesis and the toxic consequences of its disruption. Biochem Soc Trans. (2001) 29(Pt 6):831-5. doi: 10.1042/0300-5127: 0290831 
18. Pewzner-Jung Y, Ben-Dor S, Futerman AH. When do Lasses (longevity assurance genes) become CerS (ceramide synthases)? Insights into the regulation of ceramide synthesis. J Biol Chem. (2006) 281:250015. doi: 10.1074/jbc.R600010200

19. Causeret C, Geeraert L, Van der Hoeven G, Mannaerts GP, Van Veldhoven PP. Further characterization of rat dihydroceramide desaturase: tissue distribution, subcellular localization, and substrate specificity. Lipids. (2000) 35:1117-25. doi: 10.1007/s11745-000-0627-6

20. Hannun YA, Obeid LM. Principles of bioactive lipid signalling: lessons from sphingolipids. Nat Rev Molecul Cell Biol. (2008) 9:139-50. doi: 10.1038/nrm2329

21. Xu R, Jin J, Hu W, Sun W, Bielawski J, Szulc Z, et al. Golgi alkaline ceramidase regulates cell proliferation and survival by controlling levels of sphingosine and S1P. FASEB J. (2006) 20:1813-25. doi: 10.1096/fj.05-5689com

22. Galadari S, Wu BX, Mao C, Roddy P, El Bawab S, Hannun YA. Identification of a novel amidase motif in neutral ceramidase. Biochem J. (2006) 393:68795. doi: 10.1042/BJ20050682

23. Spiegel S, Milstien S. The outs and the ins of sphingosine-1-phosphate in immunity. Nat Rev Immunol. (2011) 11:403-15. doi: 10.1038/nri2974

24. Mechtcheriakova D, Wlachos A, Sobanov J, Kopp T, Reuschel $\mathrm{R}$, Bornancin $\mathrm{F}$, et al. Sphingosine 1-phosphate phosphatase 2 is induced during inflammatory responses. Cell Signal. (2007) 19:748-60. doi: 10.1016/j.cellsig.2006.09.004

25. Peest U, Sensken SC, Andréani P, Hänel P, Van Veldhoven PP, Gräler MH. S1P-lyase independent clearance of extracellular sphingosine 1-phosphate after dephosphorylation and cellular uptake. J Cell Biochem. (2008) 104:75672. doi: $10.1002 /$ jcb. 21665

26. Johnson KR, Johnson KY, Becker KP, Bielawski J, Mao C, Obeid LM. Role of human sphingosine-1-phosphate phosphatase 1 in the regulation of intraand extracellular sphingosine-1-phosphate levels and cell viability. J Biol Chem. (2003) 278:34541-7. doi: 10.1074/jbc.M301741200

27. Sigal YJ, Mcdermott MI, Morris AJ. Integral membrane lipid phosphatases/phosphotransferases: common structure and diverse functions. Biochem J. (2005) 387:281-93. doi: 10.1042/BJ20041771

28. Weske S, Vaidya M, Reese A, Lipinski KV, Keul P, Bayer JK, et al. Targeting sphingosine-1-phosphate lyase as an anabolic therapy for bone loss. Nat Med. (2018) 24:667-8. doi: 10.1038/s41591-018-0005-y

29. Ito K, Anada $Y$, Tani M, Ikeda M, Sano T, Kihara A, et al. Lack of sphingosine 1-phosphate-degrading enzymes in erythrocytes. Biochem Biophys Res Commun. (2007) 357:212-7. doi: 10.1016/j.bbrc.2007.03.123

30. Rosen H, Gonzalez-Cabrera PJ, Sanna MG, Brown S. Sphingosine 1phosphate receptor signaling. Annual Rev Biochem. (2009) 78:74368. doi: 10.1146/annurev.biochem.78.072407.103733

31. Pappu R, Schwab SR, Cornelissen I, Pereira JP, Regard JB, Xu Y, et al. Promotion of lymphocyte egress into blood and lymph by distinct sources of sphingosine-1-phosphate. Science. (2007) 316:2958. doi: $10.1126 /$ science. 1139221

32. Schwab SR, Pereira JP, Matloubian M, Xu Y, Huang Y, Cyster JG. Lymphocyte sequestration through S1P lyase inhibition and disruption of S1P gradients. Science. (2005) 309:1735-9. doi: 10.1126/science.1113640

33. Venkataraman K, Lee YM, Michaud J, Thangada S, Ai Y, Bonkovsky HL, et al. Vascular endothelium as a contributor of plasma sphingosine 1-phosphate. Circul Res. (2008) 102:669-76. doi: 10.1161/CIRCRESAHA.107.165845

34. Ryu J, Kim HJ, Chang EJ, Huang H, Banno Y, Kim HH. Sphingosine 1-phosphate as a regulator of osteoclast differentiation and osteoclast-osteoblast coupling. EMBO J. (2006) 25:584051. doi: 10.1038/sj.emboj.7601430

35. Hait NC, Oskeritzian CA, Paugh SW, Milstien S, Spiegel S. Sphingosine kinases, sphingosine 1-phosphate, apoptosis and diseases. Biochim Biophys Acta. (2006) 1758:2016-26. doi: 10.1016/j.bbamem.2006.08.007

36. Pitson SM. Regulation of sphingosine kinase and sphingolipid signaling. Trends Biochem Sci. (2011) 36:97-107. doi: 10.1016/j.tibs.2010. 08.001

37. Strub GM, Paillard M, Liang J, Gomez L, Allegood JC, Hait NC, et al. Sphingosine-1-phosphate produced by sphingosine kinase 2 in mitochondria interacts with prohibitin 2 to regulate complex IV assembly and respiration. FASEB J. (2011) 25:600-12. doi: 10.1096/fj.10-167502
38. Hait NC, Allegood J, Maceyka M, Strub GM, Harikumar KB, Singh SK, et al. Regulation of histone acetylation in the nucleus by sphingosine-1-phosphate. Science. (2009) 325:1254-7.

39. Selvam SP, De Palma RM, Oaks JJ, Oleinik N, Peterson YK, Stahelin RV, et al. Binding of the sphingolipid S1P to hTERT stabilizes telomerase at the nuclear periphery by allosterically mimicking protein phosphorylation. Sci Signal. (2015) 8:ARTN ra58. doi: 10.1126/scisignal.aaa4998

40. Riccio A. New endogenous regulators of class I histone deacetylases. Sci Signal. (2010) 3:ARTN pe1. doi: 10.1126/scisignal.3103pe1

41. Alvarez SE, Harikumar KB, Hait NC, Allegood J, Strub GM, Kim EY, et al. Sphingosine-1-phosphate is a missing cofactor for the E3 ubiquitin ligase TRAF2. Nature. (2010) 465:1084-8. doi: 10.1038/nature09128

42. Nishi T, Kobayashi N, Hisano Y, Kawahara A, Yamaguchi A. Molecular and physiological functions of sphingosine 1-phosphate transporters. Bba-Mol Cell Biol L. (2014) 1841:759-65. doi: 10.1016/j.bbalip.2013.07.012

43. Spiegel S, Maczis MA, Maceyka M, Milstien S. New insights into functions of the sphingosine-1-phosphate transporter SPNS2. J Lipid Res. (2019) 60:4849. doi: 10.1194/jlr.S091959

44. Kim RH, Takabe K, Milstien S, Spiegel S. Export and functions of sphingosine-1-phosphate. Bba-Mol Cell Biol L. (2009) 1791:6926. doi: 10.1016/j.bbalip.2009.02.011

45. Kobayashi N, Kobayashi N, Yamaguchi A, Nishi T. Characterization of the ATP-dependent Sphingosine 1-phosphate transporter in rat erythrocytes. $J$ Biol Chem. (2009) 284:21192-200. doi: 10.1074/jbc.M109.006163

46. Kobayashi N, Nishi T, Hirata T, Kihara A, Sano T, Igarashi Y, et al. Sphingosine 1-phosphate is released from the cytosol of rat platelets in a carrier-mediated manner. J Lipid Res. (2006) 47:61421. doi: 10.1194/jlr.M500468-JLR200

47. Nieuwenhuis B, Luth A, Jakobi M, Kleuser B. Involvement of the Abc-Transporter Abccl and the Sphingosine 1-Phosphate Receptor Subtype S1p3 in the cytoprotection of human fibroblasts by the glucocorticoid dexamethasone. Naunyn Schmiedebergs Arch. Pharmacol. (2010) 382:21. doi: 10.1007/s00109-009-0468-x

48. Takabe K, Kim RH, Allegood JC, Mitra P, Ramachandran S, Nagahashi $\mathrm{M}$, et al. Estradiol induces export of sphingosine 1-phosphate from breast cancer cells via ABCC1 and ABCG2. J Biol Chem. (2010) 285:1047786. doi: 10.1074/jbc.M109.064162

49. Tanfin Z, Serrano-Sanchez M, Leiber D. ATP-binding cassette ABCC1 is involved in the release of sphingosine 1-phosphate from rat uterine leiomyoma ELT3 cells and late pregnant rat myometrium. Cell Signal. (2011) 23:1997-2004. doi: 10.1016/j.cellsig.2011.07.010

50. Vu TM, Ishizu AN, Foo JC, Toh XR, Zhang FY, Whee DM, et al. Mfsd2b is essential for the sphingosine-1-phosphate export in erythrocytes and platelets. Nature. (2017) 550:524-8. doi: 10.1038/nature24053

51. Kobayashi N, Kawasaki-Nishi S, Otsuka M, Hisano Y, Yamaguchi A, Nishi T. MFSD2B is a sphingosine 1-phosphate transporter in erythroid cells. Sci Rep. (2018) 8:ARTN4969. doi: 10.1038/s41598-018-23300-x

52. Kawahara A, Nishi T, Hisano Y, Fukui H, Yamaguchi A, Mochizuki N. The Sphingolipid Transporter Spns2 Functions in Migration of Zebrafish Myocardial Precursors. Science. (2009) 323:524-7. doi: 10.1126/science.1167449

53. Hisano Y, Kobayashi N, Kawahara A, Yamaguchi A, Nishi T. The Sphingosine 1-phosphate transporter, SPNS2, functions as a transporter of the phosphorylated form of the immunomodulating agent FTY720. J Biol Chem. (2011) 286:1758-66. doi: 10.1074/jbc.M110.171116

54. Bougault C, El Jamal A, Briolay A, Mebarek S, Boutet MA, Garraud $\mathrm{T}$, et al. Involvement of sphingosine kinase/sphingosine 1-phosphate metabolic pathway in spondyloarthritis. Bone. (2017) 103:150-8. doi: 10.1016/j.bone.2017.07.002

55. Keller J, Catala-Lehnen P, Huebner AK, Jeschke A, Heckt T, Lueth A, et al. Calcitonin controls bone formation by inhibiting the release of sphingosine 1-phosphate from osteoclasts. Nat Commun. (2014) 5:5215 doi: $10.1038 /$ ncomms6215

56. Fukuhara S, Simmons S, Kawamura S, Inoue A, Orba Y, Tokudome T, et al. The sphingosine-1-phosphate transporter Spns2 expressed on endothelial cells regulates lymphocyte trafficking in mice. J Clin Invest. (2012) 122:141626. doi: 10.1172/JCI60746 
57. Nijnik A, Clare S, Hale C, Chen J, Raisen C, Mottram L, et al. The role of sphingosine-1-phosphate transporter Spns2 in immune system function. J Immunol. (2012) 189:102-11. doi: 10.4049/jimmunol.12 00282

58. Pettus BJ, Bielawski J, Porcelli AM, Reames DL, Johnson KR, Morrow J, et al. The sphingosine kinase 1/sphingosine-1-phosphate pathway mediates COX2 induction and PGE2 production in response to TNF- $\alpha$. FASEB J. (2003) 17:1411-21. doi: 10.1096/fj.02-1038com

59. Park ES, Choi S, Shin B, Yu J, Yu J, Hwang J M, et al. Tumor necrosis factor (TNF) receptor-associated factor (TRAF)-interacting protein (TRIP) negatively regulates the TRAF2 ubiquitin-dependent pathway by suppressing the TRAF2-sphingosine 1-phosphate (S1P) interaction. J Biol Chem. (2015) 290:9660-73. doi: 10.1074/jbc.M114. 609685

60. Harikumar KB, Yester JW, Surace MJ, Oyeniran C, Price MM, Huang WC, et al. K63-linked polyubiquitination of transcription factor IRF1 is essential for IL-1-induced production of chemokines CXCL10 and CCL5. Nat Immunol. (2014) 15:231-8. doi: 10.1038/ni.2810

61. Ledgerwood LG, Lal G, Zhang N, Garin A, Esses SJ, Ginhoux F, et al. The sphingosine 1-phosphate receptor 1 causes tissue retention by inhibiting the entry of peripheral tissue T lymphocytes into afferent lymphatics. Nat Immunol. (2008) 9:42-53. doi: 10.1038/ni1534

62. Kono M, Proia RL. Imaging S1P1 activation in vivo. Exp Cell Res. (2015) 333:178-82. doi: 10.1016/j.yexcr.2014.11.023

63. Sanchez T, Hla T. Structural and functional characteristics of S1P receptors. J Cell Biochem. (2004) 92:913-22. doi: 10.1002/jcb.20127

64. Davis MD, Kehrl JH. The influence of sphingosine-1-phosphate receptor signaling on lymphocyte trafficking: how a bioactive lipid mediator grew up from an "immature" vascular maturation factor to a "mature" mediator of lymphocyte behavior and function. Immunol Res. (2009) 43:18797. doi: $10.1007 /$ s12026-008-8066-5

65. Cahalan SM, Gonzalez-Cabrera PJ, Sarkisyan G, Nguyen N, Schaeffer MT, Huang L, et al. Actions of a picomolar short-acting S1P1 agonist in S1P1-eGFP knock-in mice. Nat Chem Biol. (2011) 7:254-6. doi: 10.1038/nchembio.547

66. Chae SS, Proia RL, Hla T. Constitutive expression of the S1P 1 receptor in adult tissues. Prostagland Other Lipid Med. (2004) 73:14150. doi: 10.1016/j.prostaglandins.2004.01.006

67. Kono M, Tucker AE, Tran J, Bergner JB, Turner EM, Proia RL. Sphingosine1 -phosphate receptor 1 reporter mice reveal receptor activation sites in vivo. J Clin Invest. (2014) 124:2076-86. doi: 10.1172/JCI71194

68. Cuvillier O. Sphingosine 1-phosphate receptors: from biology to physiopathology. Med Sci. (2012) 28:9517. doi: $10.1051 / \mathrm{medsci} / 20122811013$

69. Nayak D, Huo Y, Kwang W, Pushparaj P, Kumar S, Ling EA, et al. Sphingosine kinase 1 regulates the expression of proinflammatory cytokines and nitric oxide in activated microglia. Neuroscience. (2010) 166:13244. doi: 10.1016/j.neuroscience.2009.12.020

70. Liu Y, Wada R, Yamashita T, Mi Y, Deng CX, Hobson JP, et al. Edg-1, the $\mathrm{G}$ protein-coupled receptor for sphingosine-1-phosphate, is essential for vascular maturation. J Clin Invest. (2000) 106:951-61. doi: 10.1172/JCI 10905

71. Camerer E, Regard JB, Cornelissen I, Srinivasan Y, Duong DN, Palmer $\mathrm{D}$, et al. Sphingosine-1-phosphate in the plasma compartment regulates basal and inflammation-induced vascular leak in mice. J Clin Invest. (2009) 119:1871-9. doi: 10.1172/JCI38575

72. Shoham AB, Malkinson G, Krief S, Shwartz Y, Ely Y, Ferrara N, et al. S1P1 inhibits sprouting angiogenesis during vascular development. Development. (2012) 139:3859-69. doi: 10.1242/dev.078550

73. Gaengel K, Niaudet C, Hagikura K, Laviña B, Muhl L, Hofmann JJ, et al. The sphingosine-1-phosphate receptor S1PR1 restricts sprouting angiogenesis by regulating the interplay between VE-cadherin and VEGFR2. Dev Cell. (2012) 23:587-99. doi: 10.1016/j.devcel.2012.08.005

74. Jung B, Obinata H, Galvani S, Mendelson K, Ding BS, Skoura A, et al. Flow-regulated endothelial S1P receptor-1 signaling sustains vascular development. Dev Cell. (2012) 23:600-10. doi: 10.1016/j.devcel.2012.07.015

75. Mendelson K, Evans T, Hla T. Sphingosine 1-phosphate signalling. Development. (2014) 141:5-9. doi: 10.1242/dev.094805
76. Eskan MA, Rose BG, Benakanakere MR, Zeng Q, Fujioka D, Martin MH, et al. TLR4 and S1P receptors cooperate to enhance inflammatory cytokine production in human gingival epithelial cells. Eur J Immunol. (2008) 38:1138-47. doi: 10.1002/eji.200737898

77. Pitson SM, Pébay A. Regulation of stem cell pluripotency and neural differentiation by lysophospholipids. Neurosignals. (2009) 17:242-54. doi: 10.1159/00023189

78. Ishii M, Egen JG, Klauschen F, Meier-Schellersheim M, Saeki Y, Vacher J, et al. Sphingosine-1-phosphate mobilizes osteoclast precursors and regulates bone homeostasis. Nature. (2009) 458:524-8. doi: 10.1038/nature07713

79. Kini U, Nandeesh B. Physiology of bone formation, remodeling, and metabolism. In: Fogelman I, Gnanasegaran G, van der Wall H, editors. Radionuclide and Hybrid Bone Imaging. Berlin; Heidelberg: Springer (2012). p. 29-57. doi: 10.1007/978-3-642-02400-9_2

80. Lacey D, Timms E, Tan HL, Kelley M, Dunstan C, Burgess T, et al. Osteoprotegerin ligand is a cytokine that regulates osteoclast differentiation and activation. Cell. (1998) 93:165-76. doi: 10.1016/S0092-8674(00)81569-X

81. Theill LE, Boyle WJ, Penninger JM. RANK-L and RANK: T cells, bone loss, and mammalian evolution. Annu Rev Immunol. (2002) 20:795823. doi: 10.1146/annurev.immunol.20.100301.064753

82. Kong YY, Yoshida H, Sarosi I, Tan HL, Timms E, Capparelli C, et al. OPGL is a key regulator of osteoclastogenesis, lymphocyte development and lymph-node organogenesis. Nature. (1999) 397:315-23. doi: 10.1038/ 16852

83. Yoshida H, Hayashi SI, Kunisada T, Ogawa M, Nishikawa S, Okamura $\mathrm{H}$, et al. The murine mutation osteopetrosis is in the coding region of the macrophage colony stimulating factor gene. Nature. (1990) 345:4424. doi: $10.1038 / 345442 \mathrm{a} 0$

84. Udagawa N, Takahashi N, Akatsu T, Tanaka H, Sasaki T, Nishihara T, et al. Origin of osteoclasts: mature monocytes and macrophages are capable of differentiating into osteoclasts under a suitable microenvironment prepared by bone marrow-derived stromal cells. Proc Natl Acad Sci USA. (1990) 87:7260-4. doi: $10.1073 /$ pnas.87.18.7260

85. Komori T. Signaling networks in RUNX2-dependent bone development. J Cell Biochem. (2011) 112:750-5. doi: 10.1002/jcb.22994

86. Cai T, Sun D, Duan Y, Wen P, Dai C, Yang J, et al. WNT/ $\beta$-catenin signaling promotes VSMCs to osteogenic transdifferentiation and calcification through directly modulating Runx2 gene expression. Exp Cell Res. (2016) 345:206-17. doi: 10.1016/j.yexcr.2016.06.007

87. Wu M, Chen G, Li YP. TGF- $\beta$ and BMP signaling in osteoblast, skeletal development, and bone formation, homeostasis and disease. Bone Res. (2016) 4:16009. doi: 10.1038/boneres.2016.9

88. Potier E, Ferreira E, Andriamanalijaona R, Pujol JP, Oudina K, LogeartAvramoglou D, et al. Hypoxia affects mesenchymal stromal cell osteogenic differentiation and angiogenic factor expression. Bone. (2007) 40:107887. doi: 10.1016/j.bone.2006.11.024

89. Yue R, Zhou BO, Shimada IS, Zhao Z, Morrison SJ. Leptin receptor promotes adipogenesis and reduces osteogenesis by regulating mesenchyma stromal cells in adult bone marrow. Cell Stem Cell. (2016) 18:78296. doi: 10.1016/j.stem.2016.02.015

90. Simonet W, Lacey D, Dunstan C, Kelley M, Chang MS, Lüthy R, et al. Osteoprotegerin: a novel secreted protein involved in the regulation of bone density. Cell. (1997) 89:309-19. doi: 10.1016/S0092-8674(00)80209-3

91. Rodan GA, Martin TJ. Therapeutic approaches to bone diseases. Science. (2000) 289:1508-14. doi: 10.1126/science.289.5484.1508

92. Taubman MA, Valverde P, Han X, Kawai T. Immune response: the key to bone resorption in periodontal disease. J Periodontol. (2005) 76:203341. doi: 10.1902/jop.2005.76.11-S.2033

93. Wang CY, Stashenko P. Characterization of bone-resorbing activity in human periapical lesions. $J$ Endodont. (1993) 19:107-11. doi: 10.1016/S0099-2399(06)80503-0

94. Ishii M, Kikuta J, Shimazu Y, Meier-Schellersheim M, Germain RN. Chemorepulsion by blood S1P regulates osteoclast precursor mobilization and bone remodeling in vivo. J Exp Med. (2010) 207:2793-8. doi: 10.1084/jem.20101474

95. Kikuta J, Kawamura S, Okiji F, Shirazaki M, Sakai S, Saito H, et al. Sphingosine-1-phosphate-mediated osteoclast precursor monocyte migration is a critical point of control in antibone-resorptive action 
of active vitamin D. Proc Natl Acad Sci USA. (2013) 110:700913. doi: $10.1073 /$ pnas.1218799110

96. Matsuzaki E, Hiratsuka S, Hamachi T, Takahashi-Yanaga F, Hashimoto Y, Higashi K, et al. Sphingosine-1-phosphate promotes the nuclear translocation of $\beta$-catenin and thereby induces osteoprotegerin gene expression in osteoblast-like cell lines. Bone. (2013) 55:315-24. doi: 10.1016/j.bone.2013.04.008

97. Higashi K, Matsuzaki E, Hashimoto Y, Takahashi-Yanaga F, Takano A, Anan $\mathrm{H}$, et al. Sphingosine-1-phosphate/S1PR2-mediated signaling triggers Smad1/5/8 phosphorylation and thereby induces Runx2 expression in osteoblasts. Bone. (2016) 93:1-11. doi: 10.1016/j.bone.2016.09.003

98. Lotinun S, Kiviranta R, Matsubara T, Alzate JA, Neff L, Lüth A, et al. Osteoclast-specific cathepsin $\mathrm{K}$ deletion stimulates S1P-dependent bone formation. J Clin Invest. (2013) 123:666-81. doi: 10.1172/JCI64840

99. Dewhirst FE, Stashenko PP, Mole JE, Tsurumachi T. Purification and partial sequence of human osteoclast-activating factor: identity with interleukin 1 beta. J Immunol. (1985) 135:2562-8. Available online at: http://www. jimmunol.org/content/135/4/2562

100. Takayanagi H. Osteoimmunology: shared mechanisms and crosstalk between the immune and bone systems. Nat Rev Immunol. (2007) 7:292304. doi: $10.1038 /$ nri2062

101. Nauta AJ, Fibbe WE. Immunomodulatory properties of mesenchymal stromal cells. Blood (2007) 110:3499506. doi: 10.1182/blood-2007-02-069716

102. Kim MS, Day CJ, Morrison NA. MCP-1 is induced by RANKL, promotes osteoclast fusion and rescues GM-CSF suppression of osteoclast formation. $J$ Biol Chem. (2005) 280:16163-9. doi: 10.1074/jbc.M412713200

103. Miyamoto T, Ohneda O, Arai F, Iwamoto K, Okada S, Takagi K, et al. Bifurcation of osteoclasts and dendritic cells from common progenitors. Blood. (2001) 98:2544-54. doi: 10.1182/blood.V98.8.2544

104. Lari R, Fleetwood AJ, Kitchener PD, Cook AD, Pavasovic D, Hertzog PJ, et al. Macrophage lineage phenotypes and osteoclastogenesisComplexity in the control by GM-CSF and TGF- $\beta$. Bone. (2007) 40:32336. doi: 10.1016/j.bone.2006.09.003

105. Takayanagi H, Ogasawara K, Hida S, Chiba T, Murata S, Sato K, et al. T-cell-mediated regulation of osteoclastogenesis by signalling cross-talk between RANKL and IFN- $\gamma$. Nature. (2000) 408:600-5. doi: 10.1038/35 046102

106. Lee MS, Kim HS, Yeon JT, Choi SW, Chun CH, Kwak HB, et al. GM-CSF regulates fusion of mononuclear osteoclasts into bone-resorbing osteoclasts by activating the Ras/ERK pathway. J Immunol. (2009) 183:33909. doi: $10.4049 /$ jimmunol.0804314

107. Park BK, Zhang H, Zeng Q, Dai J, Keller ET, Giordano T, et al. NF-KB in breast cancer cells promotes osteolytic bone metastasis by inducing osteoclastogenesis via GM-CSF. Nat Med. (2007) 13:629. doi: $10.1038 / \mathrm{nm} 1519$

108. Abu-Amer Y. IL-4 abrogates osteoclastogenesis through STAT6dependent inhibition of NF-кB. J Clin Invest. (2001) 107:137585. doi: 10.1172/JCI10530

109. Moreno JL, Kaczmarek M, Keegan AD, Tondravi M. IL-4 suppresses osteoclast development and mature osteoclast function by a STAT6-dependent mechanism: irreversible inhibition of the differentiation program activated by RANKL. Blood. (2003) 102:1078-86. doi: 10.1182/blood-2002-11-3437

110. Park-Min KH, Ji JD, Antoniv T, Reid AC, Silver RB, Humphrey MB, et al. IL-10 suppresses calcium-mediated costimulation of receptor activator NF$\kappa \mathrm{B}$ signaling during human osteoclast differentiation by inhibiting TREM-2 expression. J Immunol. (2009) 183:2444-55. doi: 10.4049/jimmunol.0804165

111. Kudo O, Sabokbar A, Pocock A, Itonaga I, Fujikawa Y, Athanasou $\mathrm{N}$. Interleukin-6 and interleukin-11 support human osteoclast formation by a RANKL-independent mechanism. Bone. (2003) 32:1-7. doi: 10.1016/S8756-3282(02)00915-8

112. Hashizume M, Hayakawa N, Mihara M. IL-6 trans-signalling directly induces RANKL on fibroblast-like synovial cells and is involved in RANKL induction by TNF- $\alpha$ and IL-17. Rheumatology. (2008) 47:163540. doi: 10.1093/rheumatology/ken363

113. Kurihara N, Bertolini D, Suda T, Akiyama Y, Roodman GD. IL-6 stimulates osteoclast-like multinucleated cell formation in long term human marrow cultures by inducing IL-1 release. J Immunol. (1990) 144:4226-30.

114. Korn T, Mitsdoerffer M, Croxford AL, Awasthi A, DardalhonVA, Galileos G, et al. IL-6 controls Th17 immunity in vivo by inhibiting the conversion of conventional T cells into Foxp3+ regulatory T cells. Proc Natl Acad Sci USA. (2008) 105:18460-5. doi: 10.1073/pnas.0809850105

115. Kimura A, Naka T, Kishimoto T. IL-6-dependent and-independent pathways in the development of interleukin 17-producing T helper cells. Proc Natl Acad Sci USA. (2007) 104:12099-104. doi: 10.1073/pnas.0705268104

116. Lubberts E, van den Bersselaar L, Oppers-Walgreen B, Schwarzenberger P, Coenen-de Roo CJ, Kolls JK, et al. IL-17 promotes bone erosion in murine collagen-induced arthritis through loss of the receptor activator of NF-кB ligand/osteoprotegerin balance. J Immunol. (2003) 170:265562. doi: $10.4049 /$ jimmunol.170.5.2655

117. Van Den Berg WB, Miossec P. IL-17 as a future therapeutic target for rheumatoid arthritis. Nat Rev Rheumatol. (2009) 5:549-53. doi: 10.1038/nrrheum.2009.179

118. Sakaguchi S, Yamaguchi T, Nomura T, Ono M. Regulatory $\mathrm{T}$ cells and immune tolerance. Cell. (2008) 133:775-87. doi: 10.1016/j.cell.2008.05.009

119. Zaiss MM, Axmann R, Zwerina J, Polzer K, Gückel E, Skapenko A, et al. Treg cells suppress osteoclast formation: a new link between the immune system and bone. Arthrit Rheumat. (2007) 56:4104-12. doi: 10.1002/art.23138

120. Quinn JM, Itoh K, Udagawa N, Häusler K, Yasuda H, Shima N, et al. Transforming growth factor $\beta$ affects osteoclast differentiation via direct and indirect actions. J BoneMineral Res. (2001) 16:178794. doi: 10.1359/jbmr.2001.16.10.1787

121. Galvin RJS, Gatlin CL, Horn JW, Fuson TR. TGF- $\beta$ enhances osteoclast differentiation in hematopoietic cell cultures stimulated with RANKL and M-CSF. Biochem Biophys Res Commun. (1999) 265:233-9. doi: 10.1006/bbrc.1999.1632

122. Mills CD, Kincaid K, Alt JM, Heilman MJ, Hill A. M. M-1/M-2 macrophages and the Th1/Th2 paradigm. J Immunol. (2000) 164:616673. doi: 10.4049/jimmunol.164.12.6166

123. Horwood NJ. Macrophage polarization and bone formation: a review. Clin Rev Allergy Immunol. (2016) 51:79-86. doi: 10.1007/s12016-015-8519-2

124. Mantovani A, Sica A, Sozzani S, Allavena P, Vecchi A, Locati M. The chemokine system in diverse forms of macrophage activation and polarization. Trends Immunol. (2004) 25:67786. doi: 10.1016/j.it.2004.09.015

125. Murray PJ, Allen JE, Biswas SK, Fisher EA, Gilroy DW, Goerdt S, et al. Macrophage activation and polarization: nomenclature and experimental guidelines. Immunity. (2014) 41:14-20. doi: 10.1016/j.immuni.2014. 06.008

126. Takeshita S, Kaji K, Kudo A. Identification and characterization of the new osteoclast progenitor with macrophage phenotypes being able to differentiate into mature osteoclasts. J Bone Mineral Res. (2000) 15:147788. doi: 10.1359/jbmr.2000.15.8.1477

127. Wei S, Kitaura H, Zhou P, Ross FP, Teitelbaum SL. IL-1 mediates TNF-induced osteoclastogenesis. J Clin Invest. (2005) 115:282-90. doi: 10.1172/JCI200523394

128. Zwerina J, Redlich K, Polzer K, Joosten L, Krönke G, Distler J, et al. TNFinduced structural joint damage is mediated by IL-1. Proc Natl Acad Sci USA. (2007) 104:11742-7. doi: 10.1073/pnas.0610812104

129. Lam J, Takeshita S, Barker JE, Kanagawa O, Ross FP, Teitelbaum SL. TNF- $\alpha$ induces osteoclastogenesis by direct stimulation of macrophages exposed to permissive levels of RANK ligand. J Clin Invest. (2000) 106:14818. doi: 10.1172/JCI11176

130. Kobayashi K, Takahashi N, Jimi E, Udagawa N, Takami M, Kotake S, et al. Tumor necrosis factor $\alpha$ stimulates osteoclast differentiation by a mechanism independent of the ODF/RANKL-RANK interaction. J Exp Med. (2000) 191:275-86. doi: 10.1084/jem.191.2.275

131. Kitaura H, Sands MS, Aya K, Zhou P, Hirayama T, Uthgenannt B, et al. Marrow stromal cells and osteoclast precursors differentially contribute to TNF- $\alpha$-induced osteoclastogenesis in vivo. J Immunol. (2004) 173:483846. doi: 10.4049/jimmunol.173.8.4838

132. Zou W, Hakim I, Tschoep K, Endres S, Bar-Shavit Z, Tumor necrosis factor$\alpha$ mediates RANK ligand stimulation of osteoclast differentiation by an autocrine mechanism. J Cell Biochem. (2001) 83:70-83. doi: 10.1002/jcb.1202 
133. Ho VW, Sly LM. Derivation and characterization of murine alternatively activated (M2) macrophages. Methods Mol Biol. (2009) 531:173-85. doi: 10.1007/978-1-59745-396-7_12

134. Bonewald L, Dallas S. Role of active and latent transforming growth factor $\beta$ in bone formation. J Cell Biochem. (1994) 55:350-7. doi: $10.1002 / j c b .240550312$

135. Wu B, Sondag G, Malcuit C, Kim MH, Safadi FF. Macrophageassociated osteoactivin/GPNMB mediates mesenchymal stem cell survival, proliferation, and migration via a CD44-dependent mechanism. J Cellul Biochem. (2015) 117:1511-21. doi: 10.1002/jcb.25394

136. Cho TJ, Kim J, Chung C, Yoo W, Gerstenfeld L, Einhorn T, et al. Expression and role of interleukin-6 in distraction osteogenesis. Calcified Tissue Int. (2007) 80:192-200. doi: 10.1007/s00223-006-0240-y

137. Sammons J, Ahmed N, El-Sheemy M, Hassan H. The role of BMP-6, IL-6, and BMP-4 in mesenchymal stem cell-dependent bone development: effects on osteoblastic differentiation induced by parathyroid hormone and vitamin D3. Stem Cells Dev. (2004) 13:273-80. doi: 10.1089/154732804323099208

138. Blanchard F, Duplomb L, Baud'huin M, Brounais B. The dual role of IL6-type cytokines on bone remodeling and bone tumors. Cytokine Growth Factor Rev. (2009) 20:19-28. doi: 10.1016/j.cytogfr.2008.11.004

139. Itoh $\mathrm{S}$, Udagawa $\mathrm{N}$, Takahashi $\mathrm{N}$, Yoshitake $\mathrm{F}$, Narita $\mathrm{H}$, Ebisu $\mathrm{S}$, et al. A critical role for interleukin-6 family-mediated Stat 3 activation in osteoblast differentiation and bone formation. Bone. (2006) 39:50512. doi: 10.1016/j.bone.2006.02.074

140. Bellido T, Borba VZ, Roberson P, Manolagas SC. Activation of the janus kinase/STAT (Signal Transducer and Activator of Transcription) signal transduction pathway by interleukin-6-type cytokines promotes osteoblast differentiation 1. Endocrinology. (1997) 138:3666-76. doi: 10.1210/en.138.9.3666

141. Song HY, Jeon ES, Kim JI, Jung JS, Kim JH. Oncostatin M promotes osteogenesis and suppresses adipogenic differentiation of human adipose tissue-derived mesenchymal stem cells. J Cell Biochem. (2007) 101:123851. doi: $10.1002 /$ jcb. 21245

142. Guihard P, Danger Y, Brounais B, David E, Brion R, Delecrin J, et al. Induction of osteogenesis in mesenchymal stem cells by activated monocytes/macrophages depends on oncostatin M signaling. Stem Cells. (2012) 30:762-72. doi: 10.1002/stem.1040

143. Sonomoto K, Yamaoka K, Oshita K, Fukuyo S, Zhang X, Nakano K, et al. Interleukin- $1 \beta$ induces differentiation of human mesenchymal stem cells into osteoblasts via the Wnt-5a/receptor tyrosine kinase-like orphan receptor 2 pathway. Arthr Rheum. (2012) 64:3355-63. doi: 10.1002/art. 34555

144. Ma T, Miyanishi K, Trindade MC, Genovese M, Regula D, Smith RL, et al. Interleukin 1 receptor antagonist inhibits localized bone formation in vivo. $J$ Rheumatol. (2003) 30:2547-52.

145. Huang H, Kim H, Chang E, Lee Z, Hwang S, Kim H, et al. IL-17 stimulates the proliferation and differentiation of human mesenchymal stem cells: implications for bone remodeling. Cell Death Differen. (2009) 16:133243. doi: $10.1038 /$ cdd. 2009.74

146. Ono T, Okamoto K, Nakashima T, Nitta T, Hori S, Iwakura Y, et al. IL17-producing $\gamma \delta \mathrm{T}$ cells enhance bone regeneration. Nat Commun. (2016) 7:10928. doi: 10.1038/ncomms10928

147. Hess K, Ushmorov A, Fiedler J, Brenner RE, Wirth T. TNF $\alpha$ promotes osteogenic differentiation of human mesenchymal stem cells by triggering the NF- $\mathrm{KB}$ signaling pathway. Bone. (2009) 45:367-76. doi: 10.1016/j.bone.2009.04.252

148. Nanes MS. Tumor necrosis factor- $\alpha$ : molecular and cellular mechanisms in skeletal pathology. Gene. (2003) 321:115. doi: 10.1016/S0378-1119(03)00841-2

149. Perrien DS, Brown EC, Fletcher TW, Irby DJ, Aronson J, Gao GG, et al. Interleukin-1 and tumor necrosis factor antagonists attenuate ethanol-induced inhibition of bone formation in a rat model of distraction osteogenesis. J Pharmacol Exp Therapeut. (2002) 303:9048. doi: $10.1124 /$ jpet. 102.039636

150. Ding J, Ghali O, Lencel P, Broux O, Chauveau C, Devedjian J, et al. TNF$\alpha$ and IL-1 $\beta$ inhibit RUNX2 and collagen expression but increase alkaline phosphatase activity and mineralization in human mesenchymal stem cells. Life Sci. (2009) 84:499-504. doi: 10.1016/j.lfs.2009.01.013
151. Bozec A, Bakiri L, Hoebertz A, Eferl R, Schilling AF, Komnenovic V, et al. Osteoclast size is controlled by Fra-2 through LIF/LIF-receptor signalling and hypoxia. Nature. (2008) 454:221-5. doi: 10.1038/nature07019

152. Richards CD, Langdon C, Deschamps P, Pennica D, Shaughnessy SG. Stimulation of osteoclast differentiation in vitro by mouse oncostatin $\mathrm{M}$, leukaemia inhibitory factor, cardiotrophin-1 and interleukin 6: synergy with dexamethasone. Cytokine. (2000) 12:613-21. doi: 10.1006/cyto.1999.0635

153. Dresner-Pollak R, Gelb N, Rachmilewitz D, Karmeli F, Weinreb M. Interleukin 10-deficient mice develop osteopenia, decreased bone formation, and mechanical fragility of long bones. Gastroenterology. (2004) 127:792801. doi: 10.1053/j.gastro.2004.06.013

154. Van Vlasselaer P, Borremans B, Van Den Heuvel R, Van Gorp U, de Waal Malefyt R. Interleukin-10 inhibits the osteogenic activity of mouse bone marrow. Blood. (1993) 82:2361-70.

155. Van Vlasselaer P, Borremans B, Van Gorp U, Dasch J, De Waal-Malefyt R. Interleukin 10 inhibits transforming growth factor-beta (TGF-beta) synthesis required for osteogenic commitment of mouse bone marrow cells. J Cell Biol. (1994) 124:569-77. doi: 10.1083/jcb.124.4.569

156. Croes M, Öner FC, van Neerven D, Sabir E, Kruyt MC, Blokhuis TJ, et al. Proinflammatory T cells and IL-17 stimulate osteoblast differentiation. Bone. (2016) 84:262-70. doi: 10.1016/j.bone.2016.01.010

157. Duque G, Huang DC, Macoritto M, Rivas D, Yang XF, Ste-Marie LG, et al. Autocrine regulation of interferon $\gamma$ in mesenchymal stem cells plays a role in early osteoblastogenesis. Stem Cells. (2009) 27:5508. doi: 10.1634/stemcells.2008-0886

158. Postiglione L, Di Domenico G, Montagnani S, Di Spigna G, Salzano S, Castaldo C, et al. Granulocyte-macrophage colony-stimulating factor (GM-CSF) induces the osteoblastic differentiation of the human osteosarcoma cell line SaOS-2. Calcified Tissue Int. (2003) 72:85-97. doi: 10.1007/s00223-001-2088-5

159. Liu Y, Wang L, Kikuiri T, Akiyama K, Chen C, Xu X, et al. Mesenchymal stem cell-based tissue regeneration is governed by recipient $\mathrm{T}$ lymphocytes via IFN- $\gamma$ and TNF- $\alpha$. Nat Med. (2011) 17:1594-601.

160. Kim YG, Park JW, Lee JM, Suh JY, Lee JK, Chang BS, et al. IL-17 inhibits osteoblast differentiation and bone regeneration in rat. Arch Oral Biol. (2014) 59:897-905. doi: 10.1016/j.archoralbio.2014.05.009

161. Hughes JE, Srinivasan S, Lynch KR, Proia RL, Ferdek P, Hedrick CC. Sphingosine-1-phosphate induces an antiinflammatory phenotype in macrophages. Circul Res. (2008) 102:9508. doi: 10.1161/CIRCRESAHA.107.170779

162. Dorsam G, Graeler MH, Seroogy C, Kong Y, Voice JK, Goetzl EJ Transduction of multiple effects of sphingosine 1-phosphate (S1P) on T cell functions by the S1P1 G protein-coupled receptor. J Immunol. (2003) 171:3500-7. doi: 10.4049/jimmunol.171.7.3500

163. Wang W, Huang MC, Goetzl EJ. Type 1 sphingosine 1-phosphate G protein-coupled receptor (S1P1) mediation of enhanced IL-4 generation by CD4 T cells from S1P1 transgenic mice. J Immunol. (2007) 178:488590. doi: 10.4049/jimmunol.178.8.4885

164. Huang MC, Watson SR, Liao JJ, Goetzl EJ. Th17 augmentation in OTII TCR plus T cell-selective type 1 sphingosine 1phosphate receptor double transgenic mice. J Immunol. (2007) 178:6806-13. doi: 10.4049/jimmunol.178.11.6806

165. Liao JJ, Huang MC, Goetzl EJ. Cutting edge: alternative signaling of Th17 cell development by sphingosine 1-phosphate. J Immunol. (2007) 178:54258. doi: 10.4049/jimmunol.178.9.5425

166. Liu G, Yang K, Burns S, Shrestha S, Chi H. The S1P1-mTOR axis directs the reciprocal differentiation of TH1 and Treg cells. Nat Immunol. (2010) 11:1047-56. doi: 10.1038/ni.1939

167. Huang R, Wang X, Zhou Y, Xiao Y. RANKL-induced M1 macrophages are involved in bone formation. Bone Res. (2017) 5:17019. doi: 10.1038/boneres.2017.19

168. Loi F, Córdova LA, Zhang R, Pajarinen J, Lin TH, Goodman SB, et al. The effects of immunomodulation by macrophage subsets on osteogenesis in vitro. Stem Cell Res Ther. (2016) 7:15. doi: 10.1186/s13287-0160276-5

169. Aggarwal S, Pittenger MF. Human mesenchymal stem cells modulate allogeneic immune cell responses. Blood. (2005) 105:1815-22. doi: 10.1182/blood-2004-04-1559 
170. Gur-Wahnon D, Borovsky Z, Beyth S, Liebergall M, Rachmilewitz J. Contactdependent induction of regulatory antigen-presenting cells by human mesenchymal stem cells is mediated via STAT3 signaling. Exp Hematol. (2007) 35:426-33. doi: 10.1016/j.exphem.2006.11.001

171. Németh K, Leelahavanichkul A, Yuen PS, Mayer B, Parmelee A, Doi K, et al. Bone marrow stromal cells attenuate sepsis via prostaglandin E2-dependent reprogramming of host macrophages to increase their interleukin-10 production. Nat Med. (2009) 15:42-9. doi: 10.1038/nm.1905

172. Fibbe WE, Nauta AJ, Roelofs H. Modulation of immune responses by mesenchymal stem cells. Annals N Y Acad Sci. (2007) 1106:2728. doi: 10.1196/annals.1392.025

173. Bunnell BA, Betancourt AM, Sullivan DE. New concepts on the immune modulation mediated by mesenchymal stem cells. Stem Cell Res Ther. (2010) 1:34. doi: $10.1186 /$ scrt34

174. Augello A, Tasso R, Negrini SM, Amateis A, Indiveri F, Cancedda R, et al. Bone marrow mesenchymal progenitor cells inhibit lymphocyte proliferation by activation of the programmed death 1 pathway. Eur J Immunol. (2005) 35:1482-90. doi: 10.1002/eji.200425405

175. Auletta JJ, Deans RJ, Bartholomew AM. Emerging roles for multipotent, bone marrow-derived stromal cells in host defense. Blood. (2012) 119:18019. doi: 10.1182/blood-2011-10-384354

176. Bianco P, Robey PG, Simmons PJ. Mesenchymal stem cells: revisiting history, concepts, and assays. Cell Stem Cell. (2008) 2:313-9. doi: 10.1016/j.stem.2008.03.002

177. Chen K, Wang D, Du WT, Han ZB, Ren H, Chi Y, et al. Human umbilical cord mesenchymal stem cells hUC-MSCs exert immunosuppressive activities through a PGE 2-dependent mechanism. Clin Immunol. (2010) 135:44858. doi: 10.1016/j.clim.2010.01.015

178. Maggini J, Mirkin G, Bognanni I, Holmberg J, Piazzón IM, Nepomnaschy I, et al. Mouse bone marrow-derived mesenchymal stromal cells turn activated macrophages into a regulatory-like profile. PLoS ONE. (2010) 5:e9252. doi: 10.1371/journal.pone.0009252

179. MacKenzie KF, Clark K, Naqvi S, McGuire VA, Nöehren G, Kristariyanto $\mathrm{Y}$, et al. PGE2 induces macrophage IL-10 production and a regulatory-like phenotype via a protein kinase A-SIK-CRTC3 pathway. J Immunol. (2013) 190:565-77. doi: 10.4049/jimmunol.1202462

180. Chyun YS, Raisz LG. Stimulation of bone formation by prostaglandin E2. Prostaglandins. (1984) 27:97-103. doi: 10.1016/0090-6980(84) 90223-5

181. Raicevic G, Rouas R, Najar M, Stordeur P, Boufker HI, Bron D, et al. Inflammation modifies the pattern and the function of Toll-like receptors expressed by human mesenchymal stromal cells. Hum Immunol. (2010) 71:235-44. doi: 10.1016/j.humimm.2009.12.005

182. Waterman RS, Tomchuck SL, Henkle SL, Betancourt AM. A new mesenchymal stem cell (MSC) paradigm: polarization into a proinflammatory MSC1 or an Immunosuppressive MSC2 phenotype. PLoS ONE. (2010) 5:e10088. doi: 10.1371/journal.pone.0010088

183. Verreck FA, de Boer T, Langenberg DM, van der Zanden L, Ottenhoff TH. Phenotypic and functional profiling of human proinflammatory type- 1 and anti-inflammatory type- 2 macrophages in response to microbial antigens and IFN- $\gamma$-and CD40L-mediated costimulation. J Leukocyte Biol. (2006) 79:285-93. doi: 10.1189/jlb.0105015

184. Xiao L, Zhou Y, Zhu L, Yang S, Huang R, Shi W, et al. SPHK1S1PR1-RANKL axis regulates the interactions between macrophages and BMSCs in inflammatory bone loss. J Bone Miner Res. (2018) 3:1090104. doi: 10.1002/jbmr.3396

185. Rivera J, Proia RL, Olivera A. The alliance of sphingosine-1-phosphate and its receptors in immunity. Nat Rev Immunol. (2008) 8:75363. doi: $10.1038 /$ nri2400

186. Wang F, Van Brocklyn JR, Hobson JP, Movafagh S, Zukowska-Grojec Z, Milstien S, et al. Sphingosine 1-phosphate stimulates cell migration through a Gi-coupled cell surface receptor potential involvement in angiogenesis. $J$ Biol Chem. (1999) 274:35343-50. doi: 10.1074/jbc.274.50.35343

187. Schwab SR, Cyster JG. Finding a way out: lymphocyte egress from lymphoid organs. Nat Immunol. (2007) 8:1295-301. doi: 10.1038/ni1545

188. Zachariah MA, Cyster JG. Neural crest-derived pericytes promote egress of mature thymocytes at the corticomedullary junction. Science. (2010) 328:1129-35. doi: 10.1126/science. 1188222
189. Cinamon G, Zachariah MA, Lam OM, Foss FW, Cyster JG. Follicular shuttling of marginal zone B cells facilitates antigen transport. Nat Immunol. (2008) 9:54-62. doi: 10.1038/ni1542

190. Jenne CN, Enders A, Rivera R, Watson SR, Bankovich AJ, Pereira JP, et al. T-bet-dependent S1P5 expression in NK cells promotes egress from lymph nodes and bone marrow. J Exp Med. (2009) 206:246981. doi: 10.1084/jem.20090525

191. Rathinasamy A, Czeloth N, Pabst O, Förster R, Bernhardt G. The origin and maturity of dendritic cells determine the pattern of sphingosine 1-phosphate receptors expressed and required for efficient migration. J Immunol. (2010) 185:4072-81. doi: 10.4049/jimmunol.1000568

192. König K, Diehl L, Rommerscheidt-Fuss U, Golletz C, Quast T, Kahl P, et al. Four-and-a-half LIM domain protein 2 is a novel regulator of sphingosine 1phosphate receptor 1 in CCL19-induced dendritic cell migration. J Immunol. (2010) 185:1466-75. doi: 10.4049/jimmunol.0903449

193. Jolly PS, Bektas M, Olivera A, Gonzalez-Espinosa C, Proia RL, Rivera J, et al. Transactivation of sphingosine-1-phosphate receptors by FceRI triggering is required for normal mast cell degranulation and chemotaxis. $J$ Exp Med. (2004) 199:959-70. doi: 10.1084/jem.20030680

194. Zhang L, Orban M, Lorenz M, Barocke V, Braun D, Urtz N, et al. A novel role of sphingosine 1-phosphate receptor S1pr1 in mouse thrombopoiesis. J Exp Med. (2012) 209:2165-81. doi: 10.1084/jem.20121090

195. Allende ML, Tuymetova G, Lee BG, Bonifacino E, Wu YP, Proia RL. S1P1 receptor directs the release of immature $\mathrm{B}$ cells from bone marrow into blood. J Exp \Med. (2010) 207:1113-24. doi: 10.1084/jem.20092210

196. Sinha RK, Park C, Hwang IY, Davis MD, Kehrl JH. B lymphocytes exit lymph nodes through cortical lymphatic sinusoids by a mechanism independent of sphingosine-1-phosphate-mediated chemotaxis. Immunity. (2009) 30:43446. doi: 10.1016/j.immuni.2008.12.018

197. Czeloth N, Schippers A, Wagner N, Müller W, Küster B, Bernhardt G, et al. Sphingosine-1 phosphate signaling regulates positioning of dendritic cells within the spleen. J Immunol. (2007) 179:5855-63. doi: 10.4049/jimmunol.179.9.5855

198. Maeda Y, Matsuyuki H, Shimano K, Kataoka H, Sugahara K, Chiba K. Migration of CD4 T cells and dendritic cells toward sphingosine 1-phosphate (S1P) is mediated by different receptor subtypes: S1P regulates the functions of murine mature dendritic cells via S1P receptor type J Immunol. (2007) 178:3437-46. doi: 10.4049/jimmunol.178.6.3437

199. Gräler MH, Huang MC, Watson S, Goetzl EJ. Immunological effects of transgenic constitutive expression of the type 1 sphingosine 1phosphate receptor by mouse lymphocytes. J Immunol. (2005) 174:19972003. doi: 10.4049/jimmunol.174.4.1997

200. Song J, Matsuda C, Kai Y, Nishida T, Nakajima K, Mizushima T, et al. A novel sphingosine 1-phosphate receptor agonist, 2-amino2-propanediol hydrochloride (KRP-203), regulates chronic colitis in interleukin-10 gene-deficient mice. J Pharmacol Exp Therapeut. (2008) 324:276-83. doi: 10.1124/jpet.106.119172

201. Sato K, Suematsu A, Okamoto K, Yamaguchi A, Morishita Y, Kadono $\mathrm{Y}$, et al. Th17 functions as an osteoclastogenic helper $\mathrm{T}$ cell subset that links T cell activation and bone destruction. J Exp Med. (2006) 203:267382. doi: 10.1084/jem.20061775

202. Liu G, Burns S, Huang G, Boyd K, Proia RL, Flavell RA, et al. The receptor S1P1 overrides regulatory $\mathrm{T}$ cell-mediated immune suppression through Akt-mTOR. Nat Immunol. (2009) 10:769-77. doi: 10.1038/ni.1743

203. Takeshita H, Kitano M, Iwasaki $T$, Kitano S, Tsunemi S, Sato $\mathrm{C}$, et al. Sphingosine 1-phosphate $(\mathrm{S} 1 \mathrm{P}) / \mathrm{S} 1 \mathrm{P}$ receptor 1 signaling regulates receptor activator of $\mathrm{NF}-\kappa \mathrm{B}$ ligand (RANKL) expression in rheumatoid arthritis. Biochem Biophys Res Commun. (2012) 419:154-9. doi: 10.1016/j.bbrc.2012.01.103

204. Barra G, Lepore A, Gagliardi M, Somma D, Matarazzo MR, Costabile F, et al. Sphingosine Kinases promote IL-17 expression in human T lymphocytes. Sci Rep. (2018) 8:13233. doi: 10.1038/s41598-018-31666-1

205. Choi JW, Gardell SE, Herr DR, Rivera R, Lee CW, Noguchi K, et al. FTY720 (fingolimod) efficacy in an animal model of multiple sclerosis requires astrocyte sphingosine 1-phosphate receptor 1 (S1P1) modulation. Proc Nat Acad Sci USA. (2011) 108:751-6. doi: 10.1073/pnas.1014154108

206. Kitano M, Hla T, Sekiguchi M, Kawahito Y, Yoshimura R, Miyazawa $\mathrm{K}$, et al. Sphingosine 1-phosphate/sphingosine 1-phosphate receptor 
1 signaling in rheumatoid synovium: Regulation of synovial proliferation and inflammatory gene expression. Arthr Rheum. (2006) 54:742-53. doi: $10.1002 /$ art.21668

207. Ogretmen B. Sphingolipid metabolism in cancer signalling and therapy. Nat Rev Cancer. (2018) 18:33-50. doi: 10.1038/nrc.2017.96

208. Baker DA, Barth J, Chang R, Obeid LM, Gilkeson GS. Genetic sphingosine kinase 1 deficiency significantly decreases synovial inflammation and joint erosions in murine TNF- $\alpha$-induced arthritis. J Immunol. (2010) 185:25709. doi: 10.4049/jimmunol.1000644

209. Kappos L, Antel J, Comi G, Montalban X, O'Connor P, Polman CH, et al. Oral fingolimod (FTY720) for relapsing multiple sclerosis. N Engl J Med. (2006) 355:1124-40. doi: 10.1056/NEJMoa052643

210. Sanchez T, Estrada-Hernandez T, Paik JH, Wu MT, Venkataraman $\mathrm{K}$, Brinkmann V, et al. Phosphorylation and action of the immunomodulator FTY720 inhibits vascular endothelial cell growth factor-induced vascular permeability. J Biol Chem. (2003) 278:47281-90. doi: 10.1074/jbc.M306896200

211. Kharel Y, Lee S, Snyder AH, Sheasley-O'Neill SL, Morris MA, Setiady $\mathrm{Y}$, et al. Sphingosine kinase 2 is required for modulation of lymphocyte traffic by FTY. J Biol Chem. (2005) 280:36865-72. doi: 10.1074/jbc. M506293200

212. Liu CH, Thangada S, Lee MJ, Van Brocklyn JR, Spiegel S, Hla T. Ligandinduced trafficking of the sphingosine-1-phosphate receptor EDG. Molecul Biol Cell. (1999) 10:1179-90. doi: 10.1091/mbc.10.4.1179

213. Gräler MH, Goetzl EJ. The immunosuppressant FTY720 down-regulates sphingosine 1-phosphate G-protein-coupled receptors. FASEB J. (2004) 18:551-3. doi: 10.1096/fj.03-0910fje

214. Jo E, Sanna MG, Gonzalez-Cabrera PJ, Thangada S, Tigyi G, Osborne DA, et al. S1P 1-selective in vivo-active agonists from high-throughput screening: off-the-shelf chemical probes of receptor interactions, signaling, and fate. Chem Biol. (2005) 12:703-15. doi: 10.1016/j.chembiol.2005. 04.019

215. Oo ML, Thangada S, Wu MT, Liu CH, Macdonald TL, Lynch KR, et al. Immunosuppressive and anti-angiogenic sphingosine 1-phosphate receptor1 agonists induce ubiquitinylation and proteasomal degradation of the receptor. J Biol Chem/. (2007) 282:9082-9. doi: 10.1074/jbc.M610318200

216. Oo ML, Chang SH, Thangada S, Wu MT, Rezaul K, Blaho V, et al. Engagement of S1P1-degradative mechanisms leads to vascular leak in mice. J Clin Invest. (2011) 121:2290-300. doi: 10.1172/JCI45403

217. Gonzalez-Cabrera PJ, Hla T, Rosen H. Mapping pathways downstream of sphingosine 1-phosphate subtype 1 by differential chemical perturbation and proteomics. J Biol Chem. (2007) 282:7254-64. doi: 10.1074/jbc.M610581200

218. Dyckman AJ. Modulators of Sphingosine-1-phosphate pathway biology: recent advances of sphingosine-1-phosphate Receptor 1 (S1P1) agonists and future perspectives. J Med Chem. (2017) 60:5267-89. doi: 10.1021/acs.jmedchem.6b01575

219. Tsunemi S, Iwasaki T, Kitano S, Imado T, Miyazawa K, Sano H. Effects of the novel immunosuppressant FTY720 in a murine rheumatoid arthritis model. Clin Immunol. (2010) 136:197-204. doi: 10.1016/j.clim.2010.03.428

220. Matsuura M, Imayoshi T, Okumoto T. Effect of FTY720, a novel immunosuppressant, on adjuvant- and collageninduced arthritis in rats. Int J Immunopharmacol. (2000) 22:323-31. doi: 10.1016/S0192-0561(99)00088-0

221. Han YP, Li X, Zhou QY, Jie HY, Lao XB, Han JC, et al. FTY720 Abrogates collagen-induced arthritis by hindering dendritic cell migration to local lymph nodes. J Immunol. (2015) 195:4126-35. doi: 10.4049/jimmunol.1401842

222. Miller DC, Whittington KB, Brand DD, Hasty KA, Rosloniec EF. The CII-specific autoimmune T-cell response develops in the presence of FTY720 but is regulated by enhanced Treg cells that inhibit the development of autoimmune arthritis. Arthrit Res Ther. (2016) 18:ARTN8. doi: 10.1186/s13075-015-0909-6

223. Bagdanoff JT, Donoviel MS, Nouraldeen A, Carlsen M, Jessop TC, Tarver $\mathrm{J}$, et al. Inhibition of Sphingosine 1-Phosphate Lyase for the treatment of rheumatoid arthritis: discovery of (E)-1-(4((1R,2S,3R)-1,2,3,4Tetrahydroxybutyl)-1H-imidazol-2-yl)ethanone Oxime (LX2931) and (1R,2S,3R)-1-(2-(Isoxazol-3-yl)-1H-imidazol-4-yl)butane-1,2,3,4-tetraol (LX2932). J Med Chem. (2010) 53:8650-62. doi: 10.1021/jm101183p
224. Dougados M, Baeten D. Spondyloarthritis. Lancet. (2011) 377:212737. doi: 10.1016/S0140-6736(11)60071-8

225. Yu H, Sun C, Argraves K. Periodontal inflammation and alveolar bone loss induced by Aggregatibacter actinomycetemcomitans is attenuated in sphingosine kinase 1-deficient mice. J Periodontal Res. (2016) 51:3849. doi: $10.1111 /$ jre.12276

226. Xiao L, Zhu L, Yang S, Lei D, Xiao Y, Peng B. Different correlation of sphingosine-1-phosphate receptor 1 with receptor activator of nuclear factor Kappa B ligand and regulatory T cells in rat periapical lesions. J Endodont. (2015) 41:479-86. doi: 10.1016/j.joen.2014.10.010

227. Byles V, Covarrubias AJ, Ben-Sahra I, Lamming DW, Sabatini DM, Manning, $\mathrm{BD}$, et al. The TSC-mTOR pathway regulates macrophage polarization. Nat Commun. (2013) 4:2834. doi: 10.1038/ncomms3834

228. Gulen MF, Kang Z, Bulek K, Youzhong W, Kim TW, Chen Y, et al. The receptor SIGIRR suppresses Th17 cell proliferation via inhibition of the interleukin-1 receptor pathway and mTOR kinase activation. Immunity. (2010) 32:54-66. doi: 10.1016/j.immuni.2009. 12.003

229. Zhu L, Yang T, Li L, Sun L, Hou Y, Hu X, et al. TSC1 controls macrophage polarization to prevent inflammatory disease. Nat Commun. (2014) 5:4696. doi: 10.1038/ncomms5696

230. Shao J, Zhou Y, Xiao Y. The regulatory roles of Notch in osteocyte differentiation via the crosstalk with canonical Wnt pathways during the transition of osteoblasts to osteocytes. Bone. (2018) 108:165-78. doi: 10.1016/j.bone.2018.01.010

231. Chen J, Long F. mTORC1 signaling promotes osteoblast differentiation from preosteoblasts. PLoS ONE. (2015) 10:e0130627. doi: 10.1371/journal.pone.0130627

232. Fitter S, Matthews MP, Martin SK, Xie J, Ooi SS, Walkley CR, et al. mTORC1 plays an important role in skeletal development by controlling preosteoblast differentiation. Mol Cell Biol. (2017) 37:e0066816. doi: 10.1128/MCB.00668-16

233. Chen J, Long F. mTOR signaling in skeletal development and disease. Bone Res. (2018) 6:1. doi: 10.1038/s41413-017-0004-5

234. Nollet M, Santucci-Darmanin S, Breuil V, Al-Sahlanee R, Cros C, Topi M, et al. Autophagy in osteoblasts is involved in mineralization and bone homeostasis. Autophagy. (2014) 10:1965-77. doi: 10.4161/auto. 36182

235. Ravikumar B, Vacher C, Berger Z, Davies JE, Luo S, Oroz LG, et al. Inhibition of mTOR induces autophagy and reduces toxicity of polyglutamine expansions in fly and mouse models of Huntington disease. Nat Genet. (2004) 36:585-95. doi: 10.1038/ng1362

236. Ching JK, Weihl CC. Rapamycin-induced autophagy aggravates pathology and weakness in a mouse model of VCP-associated myopathy. Autophagy. (2013) 9:799-800. doi: 10.4161/auto.23958

237. Kim J, Kundu M, Viollet B, Guan KL. AMPK and mTOR regulate autophagy through direct phosphorylation of Ulk. Nat Cell Biol. (2011) 13:13241. doi: $10.1038 / \mathrm{ncb} 2152$

238. Noda T, Ohsumi Y. Tor, a phosphatidylinositol kinase homologue, controls autophagy in yeast. J Biol Chem. (1998) 273:39636. doi: $10.1074 /$ jbc.273.7.3963

239. Schmelzle T, Hall MN. TOR, a central controller of cell growth. Cell. (2000) 103:253-62. doi: 10.1016/S0092-8674(00)00117-3

240. Xiao L. Dissecting the Role of Sphingosine 1-Phosphate-Sphingosine 1Phosphate Receptor 1 in Inflammatory Bone Remodelling. Brisbane: Queensland University of Technology (2017).

Conflict of Interest Statement: The authors declare that the research was conducted in the absence of any commercial or financial relationships that could be construed as a potential conflict of interest.

Copyright (๑) 2019 Xiao, Zhou, Friis, Beagley and Xiao. This is an open-access article distributed under the terms of the Creative Commons Attribution License (CC BY). The use, distribution or reproduction in other forums is permitted, provided the original author(s) and the copyright owner(s) are credited and that the original publication in this journal is cited, in accordance with accepted academic practice. No use, distribution or reproduction is permitted which does not comply with these terms. 